\title{
Predicting Mineral Alteration at the Potential Nuclear Waste Repository at Yucca Mountain, NV With Reactive Transport Modeling
}

\author{
W. Glassley
}

N.D. Rosenberg

April 1998

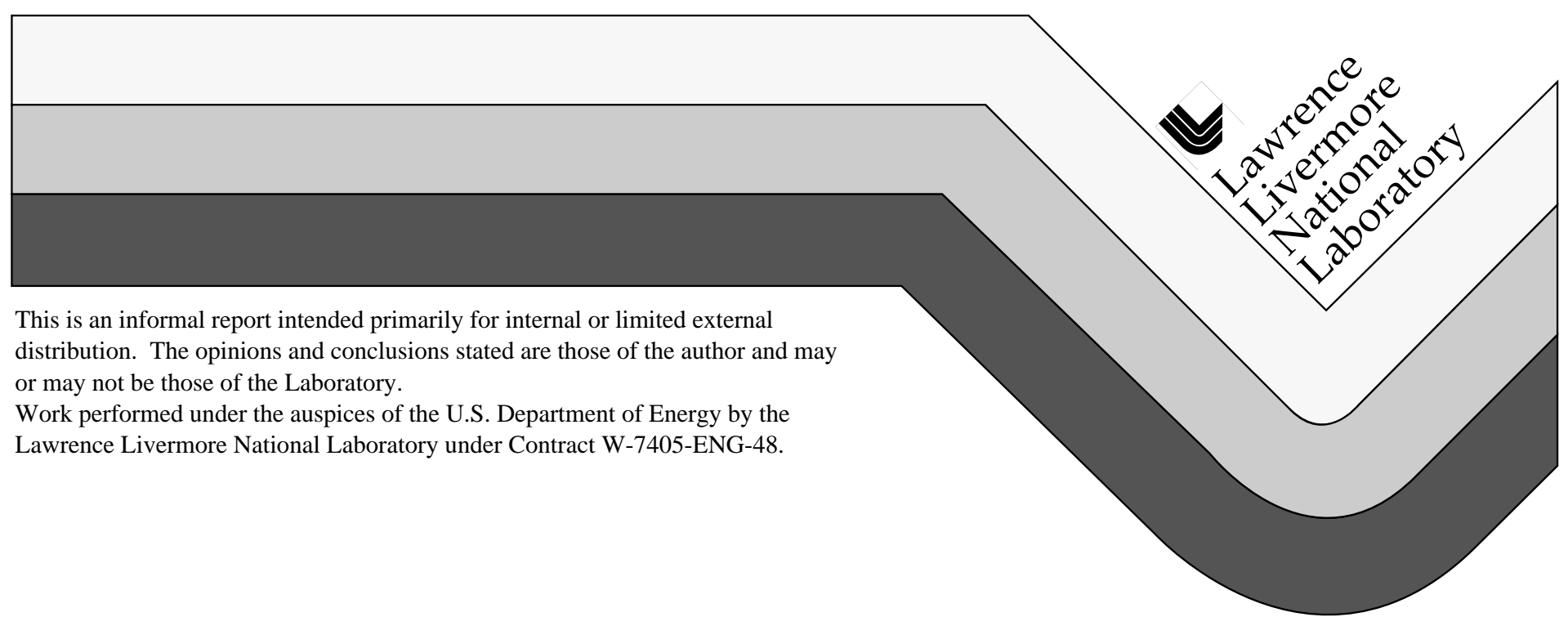




\section{DISCLAIMER}

This document was prepared as an account of work sponsored by an agency of the United States Government. Neither the United States Government nor the University of California nor any of their employees, makes any warranty, express or implied, or assumes any legal liability or responsibility for the accuracy, completeness, or usefulness of any information, apparatus, product, or process disclosed, or represents that its use would not infringe privately owned rights. Reference herein to any specific commercial product, process, or service by trade name, trademark, manufacturer, or otherwise, does not necessarily constitute or imply its endorsement, recommendation, or favoring by the United States Government or the University of California. The views and opinions of authors expressed herein do not necessarily state or reflect those of the United States Government or the University of California, and shall not be used for advertising or product endorsement purposes.

This report has been reproduced directly from the best available copy.

Available to DOE and DOE contractors from the Office of Scientific and Technical Information P.O. Box 62, Oak Ridge, TN 37831

Prices available from (423) 576-8401

Available to the public from the National Technical Information Service

U.S. Department of Commerce 5285 Port Royal Rd. Springfield, VA 22161 


\title{
PREDICTING MINERAL ALTERATION AT THE POTENTIAL NUCLEAR WASTE REPOSITORY AT YUCCA MOUNTAIN, NV WITH REACTIVE TRANSPORT MODELING
}

\author{
William Glassley \\ Nina D. Rosenberg \\ Lawrence Livermore National Laboratory \\ $4 / 2 / 98$ \\ Level 4 Milestone SPLK8CM4
}





\begin{abstract}
We present the results of a reactive transport modeling study that examines the sensitivity of mineral evolution to temperature, condensate properties and water flow conditions anticipated to occur in the potential Yucca Mountain nuclear waste repository site. We have investigated a key aspect of the thermal-hydrological repository system, the interaction of condensate water flowing through fractures at the site. Future simulations will include mineral changes at the boiling front, a process not considered in this study.

Our simulations show that the principal mineral changes that occur are dissolution of the initial phases (mainly calcite, but also feldspars and clay) and formation of zeolites and hydrated aluminous phases. Major differences in mineral alteration occur over very short distances. Fracture mineral alteration is clearly coupled with the thermal hydrological environment. Fracture porosity is enhanced in those areas where condensate forms, an upper, lower temperature condensate zone and a lower, high temperature condensate zone. The locations where mineral precipitation occur and porosity decreases depend on the integrated residence time of the solution on the fracture surface. In general, mineral precipitation is expected to occur in the region $\sim 150 \mathrm{~m}$ above the water table. Whether the changes in porosity are significant enough to modify thermohydrological behavior remains to be evaluated.
\end{abstract}


Table of Contents

$\begin{array}{ll}\text { INTRODUCTION } & 1\end{array}$

DESCRIPTION OF YUCCA MOUNTAIN SITE 2

$\begin{array}{ll}\text { Hydrogeology } & 2\end{array}$

$\begin{array}{ll}\text { Mineralogy } & 2\end{array}$

$\begin{array}{ll}\text { Thermal Hydrology } & 3\end{array}$

CONCEPTUAL MODEL $\quad 4$

$\begin{array}{ll}\text { Temperature and Flow Fields } & 4\end{array}$

$\begin{array}{ll}\text { Mineralogical and Geochemical Parameters } & 4\end{array}$

$\begin{array}{ll}\text { NUMERICAL MODEL } & 7\end{array}$

$\begin{array}{lll}\text { Conservation } & \text { Equations } & 7\end{array}$

$\begin{array}{lr}\text { Numerical Methodology } & 10\end{array}$

$\begin{array}{lr}\text { Model Setup } & 10\end{array}$

MODEL RESULTS 12

1D Simulations $r$

$\begin{array}{llr}\text { 2D Simulations } & 13\end{array}$

$\begin{array}{ll}\text { DISCUSSION } & 15\end{array}$

$\begin{array}{lr}\text { CONCLUSIONS } & 18\end{array}$

$\begin{array}{lr}\text { REFERENCES } & 19\end{array}$ 


\section{TABLES}

Table 1. Model Mineral Phases and Distribution

Table 2. Model Fluid Composition

Table 3. Model Thermodynamic Data

\section{FIGURES}

Fig. 1. Geochemical Regimes at Potential Repository

Fig. 2. 1D Model Domain, Temperature and Flow Fields

Fig. 3. 2D Model Domain, Temperature and Flow Fields

Fig. 4. 1D Model Results for Calcite

Fig. 5. 1D Model Results for K-Feldspar

Fig. 6. 1D Model Results for Stilbite

Fig. 7. 1D Model Results for Porosity

Fig. 8. 2D Model Results for Elevated $\mathrm{CO}_{2}$ Simulation

Fig. 9. 2D Model Results for Atmospheric $\mathrm{CO}_{2}$ Simulation 



\section{INTRODUCTION}

The Yucca Mountain site is currently being assessed to determine its suitability as a potential highlevel nuclear waste repository. The mineralogical evolution anticipated to occur in the potential Yucca Mountain nuclear waste repository site is important to the assessment of repository performance for three main reasons. First, changes in mineralogy will affect changes in the composition and quantity of water that may contact waste packages. This in turn affects the rate of waste package corrosion and the chemical speciation of any radionuclides migrating from the waste packages. Second, changes in mineralogy will affect the ability of the natural system to retard radionuclides by sorption, which strongly affects radionuclide travel times. Third, changes in mineralogy may alter thermal-hydrological behavior by increasing or decreasing permeability and fracture-matrix interactions. Simulations of these coupled thermal-hydrological-chemical effects may be important to the assessment of repository performance.

The potential repository is located several hundred meters below the ground surface in partially saturated, volcanic tuff. The repository will be designed to accommodate the emplacement of 70,000 metric tons of initial uranium (MTU) or equivalent spent nuclear fuel or high level waste in horizontal emplacement drifts (CRWMS M\&O, 1997). Due to the thermal flux generated by this volume of radioactive material, it is expected that temperatures within the repository will remain elevated for hundreds to thousands of years, depending on repository design. This thermal effect will create a two-phase hydrothermal system in the mountain that will persist for a similar period (Buscheck et al., 1997). The initial heat flux produced by the nuclear waste will be on the order of 50 times the heat flux in the Geysers geothermal reservoir in California (Hardin and Chestnut, 1997).

An important control on mineral development at Yucca Mountain is the interaction of condensate water, which will form in response to heating of the rock mass, and fracture-lining minerals. This condensate will develop along fracture surfaces when water vapor, formed in response to the elevated temperatures near waste packages, cools after migrating down pressure gradients. Most of the fracture minerals currently present in the rock that makes up Yucca Mountain are not in thermodynamic equilibrium with water at elevated temperatures. As a result, condensate will interact with existing fracture-lining minerals and cause new minerals to form, some existing minerals to change composition or dissolve, and water chemistry to be modified. The extent of rock-water interaction will be a function of the temperature, the duration of contact, and the alteration state of the rock at the time of interaction.

In this paper we investigate the sensitivity of mineral development to flow properties, condensate properties and temperature. We accomplished this by considering the interaction of condensate water with the mineralogy reported to occur along fracture surfaces of in situ material. Both 1-D 
and 2-D simulations were carried out, over a range of $\mathrm{CO}_{2}$ partial pressures, temperature and flow conditions. These simulations provide insight into the relative importance of the location of condensate formation, flow field properties, and temperature on dissolution of in situ minerals and precipitation of secondary minerals. Hence, they provide criteria with which to consider where and when mineralogical changes will occur in various locations in the heated region around the potential repository, and can be used to guide future model studies of the actual physical system representative of the potential repository.

\section{DESCRIPTION OF YUCCA MOUNTAIN SITE}

\section{Hydrogeology}

Yucca Mountain is composed of a sequence of quartz latite, rhyolite, and high silica rhyolite tuffs deposited as ashflow sheets about 13 million years ago. Although the rock unit within which the potential repository site is located, Topopah Springs Tuff, is completely devitrified and welded, other rock units in the vicinity are vitric or partially vitric and vary greatly in degree of welding. In some portions of the stratigraphic sequence, the rocks are also zeolitized to varying degrees. Extensive fracturing of these rocks occurred during cooling and subsequent volcanic events, and during Basin and Range tectonism.

Fractures are the primary conduits for large-scale transport of water, air, and water vapor in the welded tuff units. Fractures account for less than $1 \%$ of the total porosity, such that most of the total fluid-storage capacity is contained in the matrix pores. The permeability in the matrix is, however, very low and fractures dominate the permeability. The bulk permeability of welded tuff can be on the order of $10^{6}$ times the matrix permeability, as typically measured on a small unfractured sample. Matrix flow is relatively more important in nonwelded tuff units. The extent of matrix-fracture interaction has not been well established.

\section{Mineralogy}

A wide range of minerals has been observed in fractures sampled from boreholes and the perimeter drift at the Yucca Mountain potential repository site. An assemblage of calcite $\left(\mathrm{CaCO}_{3}\right)$ and a silica $\left(\mathrm{SiO}_{2}\right)$ polymorph (opal-CT or quartz), accompanied by minor amounts of clays and oxides is common along fractures in samples from a recent field test (Glassley and Boyd, 1995), and in samples of high-porosity, cemented breccia in drill core recovered from other in situ test sites. Other fracture minerals are alkali feldspar and zeolites including mordenite, chabazite, clinoptilolite, and heulandite. The proportions of these mineral phases are not well constrained by field observations, but calcite consistently is the dominant mineral present. The mineral assemblage along fracture surfaces varies from one location to another apparently reflecting both the 
mineralogy of the surrounding rock matrix and history of local water flux. Isotopic data has demonstrated that fractures at the repository level in the mountain that have preserved evidence of liquid water transport tend to be lined by this same suite of minerals (Paces et al., 1997). Fractures lacking these secondary minerals also lack isotopic evidence of significant water transport.

Some fracture surfaces at Yucca Mountain contain no coatings or fillings. Fluids in contact with these fracture surfaces would see only matrix minerals. Core samples indicate that the matrix of the potential repository horizon unit, Topopah Spring Tuff, is made up approximately two-thirds feldspar (2/3) and one-third $\mathrm{SiO}_{2}$ (quartz, cristobalite or tridymite). Other minerals are present in much lower amounts. Detailed descriptions and discussion of Yucca Mountain mineralogy can be found in numerous documents, including Carlos (1994) and Vaniman et al. (1997).

\section{Thermal Hydrology}

Under ambient conditions, liquid-phase fracture flow arises as a result of the percolation of rainfall and snowmelt. After waste emplacement, the heat of radioactive decay will change the spatial distribution of in situ pore fluids (air, water, and water vapor) within a large volume of rock. This thermally-driven transport of water and water vapor away from the heat source causes a redistribution of the pore fluids, including the creation of dryout zones around the emplacement drifts and the formation of condensation zones, where liquid saturation is increased from its initial value, above and below the dryout zones.

Thermal-hydrological behavior of the repository can be divided into three sequential periods: drying, quasi steady-state, and rewetting. During the initial drying period, the rate of evaporation is greater than the rate of condensation. Depending on the thermal loading of the repository, the location within the repository, and the local infiltration flux, the drying period can last from tens of years to up to a thousand years and can extend several to hundreds of meters vertically. As the repository heating rate decreases and the volume of the boiling region increases, conditions stabilize to a quasi-steady state in which the rate of evaporation is equal, or nearly equal, to the rate of condensation. This quasi-steady period may last up to several thousand years, and the drying/rewetting front may be located well away from the repository. As the repository heating rate further decreases, the rewetting period begins as temperature, liquid-phase saturation and relative humidity begin to slowly return to ambient values. A more detailed description and discussion of the near-field thermal hydrology can be found in Buscheck et al. (1997) and Hardin, et al. (1998). 


\section{CONCEPTUAL MODEL}

\section{Temperature and Flow Fields}

In response to the predicted thermal-hydrological behavior, there are four characteristic geochemical regions that develop (Fig. 1). The first region is directly below the heated region.

Water vapor driven from this area during heating will condense at approximately the location of the boiling-point isotherm and will drain under the influence of gravity toward the water table. This lower zone has a simple thermal gradient going from high temperature near the heated region toward low temperature near the water table and has fluid flux vectors that are predominately directed downward.

A second region is that which accounts for the rock mass between drifts where waste is emplaced. This region, referred to as the pillar region, extends tens of meters vertically above and below the repository horizon. The thermal conditions in this region will be complex, with highest temperatures occurring adjacent to the heated areas along the margins of the pillar region. Fluid flow here may include both water draining from the reflux zone above the heated region and condensate that forms in this region. Fluid flow through the pillar region eventually enters the lower zone, in which water flows under the influence of gravity to the saturated zone and down the local temperature gradient.

Above the heated drifts, water vapor generated during heating will migrate upward and condense in cooler regions. Within this third region, the condensed water will flow, under the influence of gravity, back toward the heated region, eventually reaching the boiling zone where it will vaporize. The vapor will again migrate upward and repeat the process, resulting in the development of a reflux zone. Above the reflux zone is a fourth region, a low temperature condensate zone. Fluid flow is expected to occur mainly in the fractures rather than the rock matrix in most of hydrogeologic units at Yucca Mountain. Accordingly, we make the simplifying assumption that consideration of only the fracture flow field will provide a reasonable description of the flow field within which much of the mineralogical evolution will occur.

\section{Mineralogical and Geochemical Parameters}

In this study, we concentrate on the interaction of minerals and water flowing though fractures. The interaction is treated as dissolution and precipitation of minerals, and represented by hydrolysis reactions of the form: 


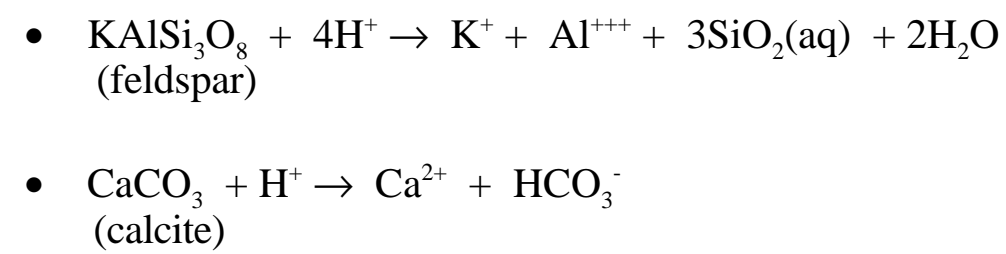

Selection of minerals to be included in the reactive transport simulations was accomplished by first conducting a suite of reaction progress simulations in which no limitations were placed on the minerals that were allowed to form. In these simulations, we used the thermodynamic model EQ3/6 (unqualified) Version 8.0 (Wolery, 1992a, 1992b; Wolery and Daveler, 1992) and the supporting "com" data base (version 6). This "com" file supports calculations over the broadest range of chemical components (more than half of the elements in the periodic table are represented) over the temperature range $0^{\circ}$ to $300^{\circ} \mathrm{C}$. It is intended to be used in conjunction with the B-dot or Davies equations and may therefore only be used in conjunction with the modeling of fairly dilute aqueous solutions (those with ionic strengths less than $0.3 \mathrm{M}$ ). Confidence in our EQ3/6 model results comes from comparisons of modeling results with laboratory experiments for tuff/groundwater interactions at elevated temperatures in well-mixed systems (e.g., Delany, 1985; Knauss and Peifer, 1986; Knauss et al., 1987).

We conducted the speciation/reaction progress simulations of tuff-fracture-water interaction at $96^{\circ} \mathrm{C}$ over a range of $\mathrm{CO}_{2}$ partial pressure conditions $\left(10^{-5}\right.$ bars to 1 bar). The reaction progress simulations were conducted using the minerals potassium feldspar, albite, quartz, cristobalite, annite, Mg-beidellite, and calcite as the reactants. These minerals were chosen as they represent both the tuff matrix and the most abundant fracture minerals observed in the repository block. They thus encompass the chemical system Na-Ca-K-Al-Si-Mg-Fe-Si- $\mathrm{CO}_{2}-\mathrm{H}_{2} \mathrm{O}-\mathrm{O}_{2}$, which describes the principal components of the rock-fracture system. We approximate the fact that the reactant feldspars are solid solutions by resolving the alkali feldspar and plagioclase compositions into the corresponding end-member K-feldspar, albite, and anorthite components.

The initial water composition is assumed to be that of condensate in equilibrium with $\mathrm{CO}_{2}$ over a range of $\mathrm{CO}_{2}$ partial pressures. Condensate waters will be created by condensation of steam. These waters will pick up some $\mathrm{O}_{2}$ and $\mathrm{CO}_{2}$ from the underground atmosphere. The levels of $\mathrm{O}_{2}$ and $\mathrm{CO}_{2}$ reacting with these waters is likely to be highly variable. The level of $\mathrm{CO}_{2}$ gas in the system is a key parameter. Analyses of in situ pore gas from the vadose zone at Yucca Mountain (Yang et al., 1988) indicate that the pore gas has $\mathrm{CO}_{2}$ contents that are elevated, relative to atmospheric values, by a factor of 1.5 to 3. Measurements of gases taken to establish the pore-gas baseline for field tests at Yucca Mountain (Glassley and DeLoach, 1997) also indicate the level of $\mathrm{CO}_{2}$ is elevated relative to atmospheric values. 
In these simulations a total of approximately 50 different secondary mineral phases participated in the reaction progress. The sequence of minerals appearing during reaction progress, and their abundances, varied depending upon reaction time and $\mathrm{CO}_{2}$ partial pressure. The mineral phases selected for inclusion in the reactive transport simulations described below are those that consistently appeared as product phases in the simulations. Minerals that appeared at abundances of less than $10^{-7}$ moles per liter of water were not included.

We also limited ourselves to the subsystem Na-Ca-K-Al-Si-CO $-\mathrm{H}_{2} \mathrm{O}$. Redox reactions involving minerals that contain $\mathrm{Fe}$ or $\mathrm{Mg}$ were eliminated from consideration due to uncertainty about the behavior of oxygen in the system. Although these components account for a small mass fraction of the rock system, they may be important in the development of the redox conditions $(\mathrm{Fe})$ and in clay and zeolite formation (Fe and $\mathrm{Mg}$ ). In general, however, it has been found that exclusion of these components, and their respective phases, has little impact on the distribution and abundance of the secondary mineral phases considered in this study. The principle differences to be expected are that no Fe-oxide or hydroxide phases will develop in these simulations, and the specific zeolite and clay mineral species occurring here (stilbite and mesolite, and kaolinite, respectively) may be partially or completely superseded by such species as clinoptilolite, heulandite, mordenite, or smectite clays. These differences are not significant for the nature and extent of mineral alteration. However, for considerations regarding radionuclide transport and effects on rock thermalhydrological properties, these differences in mineralogy may be significant.

The mineral phases included as reactants in our reactive transport model include mainly calcite, cristobalite, and kaolinite. Kaolinite is a proxy for complex smectite/illite clays. We also assume inclusion of some matrix minerals, including albite and K-feldspar (proxies for alkali feldspar), quartz and cristobalite. Since our models are based mainly on carbonate-dominated lined fractures, our results will primarily reflect the mineralogical evolution anticipated to develop along lined fractures. Nevertheless, we believe that the results are also significant for the unlined fractures in that our results represent the resulting interaction of feldspar-silica polymorph-fluid interaction, which is the dominant system in the rock matrix.

We assume a uniform fracture mineral distribution through our model and ignore differences between the various geologic units and heterogeneities within a unit. This is justified at this stage of the investigation by the small degree of variability between units (Vaniman et al., 1997) relative to the absolute variation in abundance within fractures in general.

For the reactive transport models, the same thermodynamic data were used from the "com" thermodynamic datebase. The reaction rate constants used in the calculations are based mainly on data from Johnson et al. (1998) who modeled an experimental study in which tuff-water interaction 
was monitored in a plug-flow reactor. Precipitation rates are treated as the inverse of the dissolution rates.

The mineral-reactive surface areas are extremely important in reactive transport modeling. In the 1D simulations, the mineral surfaces areas (as $\mathrm{m}^{2} / \mathrm{m}^{3}$ of rock) were estimated by first assuming that the feldspar, quartz and cristobalite phases occurred as spheres with diameters of between $\sim 0.1$ 100 microns, and were distributed uniformly along the flow field at the indicated mineral volume fractions for these phases. Calcite, amorphous silica, and kaolinite were assumed to occur as sheet-like surfaces forming fracture coatings, and hence have a much reduced surface area. For the 2-D simulations, the reactive surface areas were then modified to optimize run times, but were kept within the range of sizes indicated. Although this results in somewhat different reactive surface areas for the 1-D and 2-D suites, respectively, there are no available data to use as criteria to optimize the surfaces areas so that they accurately reflect in situ conditions. The surface-area parameter is highly uncertain and probably varies along the surface of fractures both between and within specific lithologic units. However, in the absence of additional data detailing this distribution, we have assumed that the surface area of each respective mineral phase is the same in each lithologic unit.

\section{NUMERICAL MODEL}

All reactive transport simulations were performed with the OS3D/GIMRT code (Steefel and Yabusaki, 1995).

\section{Conservation Equations}

Heat transport and fluid flow are modeled by simultaneous account of the conservation of thermal energy, which can be expressed as

$$
\rho_{m} C_{P, m} \frac{\partial T}{\partial t}=\nabla \cdot\left(\lambda_{m} \nabla T-\rho_{f} C_{P, f} \mathbf{u}_{f} T\right)
$$

and the fluid-continuity equation, which is defined by

$$
\frac{\partial\left(\phi_{m} \rho_{f}\right)}{\partial t}=-\nabla \cdot\left(\rho_{f} \mathbf{u}_{f} T\right)
$$

where $\rho$ refers to density, $C_{P}$ denotes isobaric heat capacity, $T$ stands for temperature, $t$ signifies time, $\lambda$ represents thermal conductivity, $\phi$ defines porosity, the subscripts $f$ and $m$ refer to the fluid phase and bulk medium, respectively, and the fluid flux, $\mathbf{u}_{f}$ is obtained from Darcy's law, which can be written as 


$$
\mathbf{u}_{f}=-\frac{k}{\mu_{f}}\left(\nabla P-\rho_{f} \mathbf{g}\right)
$$

where $k$ denotes permeability, $\mu$ stands for dynamic viscosity, $P$ represents pressure, and $\mathbf{g}$ is the gravity vector. As is common practice, these conservation and continuity equations reasonably neglect, as second-order effects, the potential thermal energy contributions from radioactive decay or chemical reactions and fluid-mass contributions from hydration or dehydration reactions. The continuity equation is further simplified by presuming that both the fluid and rock matrix are essentially incompressible. Moreover, in the context of these equations, the fluid phase is presumed to be pure $\mathrm{H}_{2} \mathrm{O}$, and its properties $\left(p_{f}, m_{f}\right.$, and $\left.C_{p, f}\right)$ are evaluated using several approximations to more rigorous formulations, as is typical in most models.

OS3D/GIMRT permits definition of several zones of distinct initial porosity in the model system. In its present configuration, the code cannot model any aspects of two-phase flow. Flow fields and temperature fields can be read in from data files. OS3D/GIMRT assumes saturated flow conditions.

The reaction module explicitly accounts for multicomponent chemical systems, complexation reactions in the fluid phase, and surface-controlled mineral dissolution/precipitation kinetics. The conservation of solute mass is described by

$$
\frac{\partial\left(\phi_{m} U_{j}\right)}{\partial t}+\nabla \cdot\left(\mathbf{u}_{f} U_{j}-\mathbf{D} \nabla U_{j}\right)=R_{j}^{\min }
$$

where $U_{j}$ refers to the total solution concentration of the $j$ th chemical component (accounting for a primary $j$ th solute and the $N_{i} j$-bearing complexes), $\mathbf{u}_{f} U_{j}$ and $\mathbf{D} \nabla U_{j}$ represent the advective and diffusive/dispersive fluxes, $\mathbf{D}$ stands for the dispersion/diffusion coefficient, and $R_{j}^{\min }$ denotes the reaction-rate term, which is the product $v_{j, m} r_{m}$ summed over the $N_{m}$ minerals, where $v_{j, m}$ refers to the stoichiometric coefficient of the $j$ th primary solute in the $m$ th mineral, and $r_{m}$ is the precipitation/dissolution rate for that mineral. The surface-controlled kinetic rate is given by

$$
r_{m}=\operatorname{sgn}\left(\log \left[\frac{Q_{m}}{K_{m}}\right]\right) A_{m} k_{m}\left|\left(\frac{Q_{m}}{K_{m}}\right)^{M}-1\right|^{n}
$$

where $K_{m}$ refers to the equilibrium constant for the $m$ th mineral, $Q_{m}$ stands for the associated ion activity product (defined by the numerator of the product term), $A_{m}$ denotes the reactive surface area, and $k_{m}$ is the reaction-rate constant, whose temperature dependence is accounted for by an Arrhenius equation 


$$
k_{m}=k_{25} \exp \left(-\frac{E_{a}}{R}\left[\frac{1}{T}-\frac{1}{298.15}\right]\right)
$$

where $k_{25}$ is the rate constant at $25^{\circ} \mathrm{C}, E_{a}$ represents the activation energy, $R$ stands for the gas constant, and $T$ denotes temperature (in Kelvin).

Similar to the transport equations, these specific statements of solute mass conservation and the kinetic-rate law are obtained following several simplifying approximations: all complexation (homogeneous) reactions are considered reversible (i.e., local equilibrium is imposed on the fluid phase; hence, there is no provision for treating redox disequilibria), the dispersion/diffusion coefficient of each aqueous solute is considered identical, and the rate laws are strictly linear and do not account for the inhibiting or catalyzing effect of specific aqueous solutes. With the possible exception of uniformly reversible complexation reactions, these approximations are not overly restrictive for simulating the repository altered zone. Moreover, the kinetic description avoids imposition of the local equilibrium constraint on fluid-rock (heterogeneous) reactions. There is no theoretical limit to the number of chemical components and species that can be considered, and the complexities of the nucleation process associated with mineral precipitation is dealt with by assuming that supersaturation catalyzes "instantaneous" growth of a 10-micron radius crystal. This model does not explicitly account for the effects of sorption, colloids, ion exchange, or solid solutions. Also, because the program calculates activity coefficients from an extended DebyeHückel formulation, its range of applicability is limited to systems characterized by relatively dilute aqueous solutions.

Temporal variations in the volume fraction of specific minerals as a function of irreversible dissolution/precipitation are explicitly accounted for with

$$
\frac{\partial \phi_{m}}{\partial t}=V_{m} r_{m}
$$

where $V_{m}$ refers to the standard molal volume of the subscripted mineral, and $\phi_{m}$ is the mineral volume fraction used to calculate the dependent change in porosity

$$
\phi=1-\sum_{m=1}^{N_{m}} \phi_{m}
$$


Numerical Methodology

Using an integrated finite difference scheme, OS3D/GIMRT discretizes the partial differential equations that represent the transport and reaction processes (Steefel, 1993; Steefel and Lasaga, 1994) and employs a one-step or "global implicit" method to solve the coupled nonlinear transport and reaction equations simultaneously.

In transient mode, mineral volume fractions and surface areas are held constant for the duration of each time step; in stationary-state mode, these mineral properties are held constant until the solute concentrations achieve a quasi-stationary state (Lichtner, 1992). The latter option is an efficient method for modeling systems for which the rate in mineral property variation is much slower than is the rate at which solute concentrations achieve a stationary state (Steefel, 1993).

OS3D/GIMRT can be used to conduct both 1-D and 2-D simulations and there are no restrictions to the physical scales that can be represented.

\section{Model Setup}

We performed a series of simulations in both 1D and 2D simulations. The 1D simulations were designed to evaluate the sensitivity of mineral development to the fluid flux, for a given temperature field and initial mineralogical condition. We modeled a $33 \mathrm{~m}$ column with two different temperature distributions assuming a variety of uniform, constant velocity fields (Fig. 2). The lowest velocity considered was $0.1 \mathrm{~m}^{3} \mathrm{~m}^{-2} \mathrm{yr}^{-1}$ and the highest was $1,000 \mathrm{~m}^{3} \mathrm{~m}^{-2} \mathrm{yr}^{-1}$. Simulations were run out to a time of 100 years. The first temperature field with temperatures between $40-50^{\circ} \mathrm{C}$ reflects conditions in the upper, low temperature condensate zone (Figs. 1, 2). The second temperature field with temperatures between $50-96^{\circ} \mathrm{C}$ reflects conditions in the lower, high temperature condensate zone (Figs. 1,2). The top $5 \mathrm{~m}$ of the high temperature field are representative of conditions in the reflux zone as well.

The key questions to be addressed by this suite of simulations were the time duration needed to achieve approximately steady state conditions, and how the secondary mineral and porosity distribution changed under different flow rates. The 1D simulation assumed that the initial fracture porosity was $\sim 20 \%$, in order to have available for reaction a significant volume of reactant minerals. The mineral phases considered and the initial distributions are given in Table 1. The fluid composition is that of condensate, in equilibrium with a $\mathrm{CO}_{2}$ partial pressures of $0.1 \mathrm{bar}$, approximately three times greater than atmospheric $\mathrm{CO}_{2}$ (Table 2). Values used for rate constant, activation energy and surface area are given in Table 3. 
The 2D simulations were designed to examine mineral development in response to a complex flow and temperature field more representative of likely conditions at the repository site. The region considered for the 2D study is a vertical cross-section through the mountain from the ground surface to the top of water table, $726 \mathrm{~m}$ for the model location chosen for this study. The horizontal distance extends $15 \mathrm{~m}$ from a hypothetical emplacement drift center. This 2D model considers all the geochemical regions shown in Fig. 1.

Temperature and flow fields for the 2D study were taken directly from drift-scale thermohydrologic simulations for a reference case repository design using a coupled thermal hydrological computer code (NUFT) (Nitao, 1995; Hardin et al., 1998). The NUFT simulations were run using a dual permeability formulation to describe the fracture-matrix system. In these NUFT simulations, the fracture continuum is represented by a very high porosity porous medium ( $\phi=99 \%)$ with a total fracture porosity $<<1 \%$. Since we are concerned here with only flow through fractures, we use only the fracture continuum model output. Values for the fracture liquid-phase flux vectors, fracture saturation, and the temperature were extracted from the NUFT model output at various time steps. Since we are using a liquid-phase only code, flux values were multiplied by the saturation values to estimate mass flux in an equivalent, saturated fracture continuum.

In this paper, we present results from our simulations starting with NUFT output at 1000 years. The flow and temperature fields from NUFT output at 1000 years were then held constant for a reactive transport simulation of a 5 year time period. Preliminary simulations showed that the rate of change of mineral distribution is constant by 5 years. In this case, we wanted to maintain constant porosity conditions so that our assumption of a constant flow field would be reasonable. (In the simple flow field modeled in the 1D simulations, we did not believe this to be important.) We also wanted to be able to identify qualitatively regions where porosity increased and where porosity decreased. To do this, our approach was to set the total mineral abundance very low and the porosity within the fracture very high, $\sim 99 \%$.

The domain, temperature and flow fields for the 2D simulations are shown in Fig. 3. Our strategy was to assume that condensate formation occurred at the $90^{\circ} \mathrm{C}$ isotherm and that no reactive transport occurred in the vicinity of the heated drift where conditions are at or higher than boiling, nominally $96^{\circ} \mathrm{C}$ at Yucca Mountain. That is, no reactive transport occurs in the shaded areas of Figure 3. The computational overhead involved in 2D simulations is great in these reactive transport models. We therefore simplified the mineralogy considered in the 2D simulations, relative to that considered in the $1 \mathrm{D}$ simulations, by eliminating those phases that consistently represented the least abundant phases in the 1D simulations. Model parameters are given in Tables 1-3. Two $\mathrm{CO}_{2}$ partial pressures were considered, the 0.1 bar $\mathrm{CO}_{2}$ partial pressure used in the $1 \mathrm{D}$ simulations and atmospheric $\mathrm{CO}_{2}$ partial pressure. 


\section{MODEL RESULTS}

\section{$\underline{\text { 1D Simulations }}$}

For all flow conditions, the locations of secondary phases change most significantly for the first 50 years, after which the overall pattern of mineral abundance changes more slowly. This reflects the fact that reaction rates are slow for dissolution reactions involving the phases considered.

Differences between initial and final values for calcite, K-feldspar, stilbite and porosity are shown in Figs. 4-7 for two flow rates (100 and 1,000 $\left.\mathrm{m}^{3} \mathrm{~m}^{-2} \mathrm{yr}^{-1}\right)$ and both temperature fields considered. These figures show mineral volumes and porosity as functions of position along the fracture and time.

Dissolution of the calcite in the primary mineral assemblage exhibits consistent behavior from one flow condition to another, regardless of the temperature gradient. For all cases, calcite dissolution primarily occurs in the region where condensate forms. However, the extent of dissolution is a strong function of the fluid velocity, increasing significantly as the velocity increases. Dissolution of calcite also is predominately responsible for the changes in porosity.

Amorphous silica dissolution behaves similar to calcite, in the sense that fluid velocity has little effect on the location where this phase dissolves, although unlike calcite, the extent of dissolution of this phase is relatively constant. Kaolinite dissolution occurs to about the same extent, and consistently in the same areas, regardless of flow velocity. Kaolinite is completely removed from the assemblage along most of the flow length within the region of elevated temperature in the simulations with the higher temperatures. In the low temperature simulations, kaolinite persists within the $40^{\circ} \mathrm{C}$ region but is progressively less abundant as water flow enters regions of $50^{\circ} \mathrm{C}$. Neither quartz nor albite play significant roles in the recrystallization process, remaining at or near saturation throughout the simulation period.

The formation of secondary minerals is sensitive to both the temperature and the fluid velocity. In general, the pattern that emerges is that the amount of a secondary mineral decreases as velocity increases, and increases as temperature increases, for a given location along the flow path. This pattern is clearly exhibited by stilbite abundance. Figures 4- 7 show that, at a given velocity, the abundance increases significantly along the flow field, although the relative distribution pattern remains similar. However, as velocity goes from 100 to $1,000 \mathrm{~m}^{3} / \mathrm{m}^{2} / \mathrm{yr}$ (compare Fig. 4 with 6 and Fig. 5 with 7) the abundance drops significantly, and the distribution pattern is modified. In the simulations with the higher temperature flow field, muscovite (which is closely paralleled by paragonite and diaspore, both of which occur at much lower abundances) occurs mainly as a replacement product of K-feldspar, and primarily occurs within the region where K-feldspar has dissolved. However, at very high velocities, muscovite formation is restricted to early time 
periods. The silica polymorph chalcedony occurs along the flow path at low flow velocities, but does not occur in the flow field at higher velocities, reflecting the fact that aqueous $\mathrm{SiO}_{2}$ concentrations, which are controlled by amorphous silica dissolution, decrease at any given point along the flow path, as fluid velocity increases.

To evaluate the sensitivity of the results to selection of the secondary phases, simulations were conducted with stilbite as the only Ca-rich zeolite, with mesolite as the only Ca-rich zeolite, and with both stilbite and mesolite as possible secondary phases. With the exception of muscovite, the distribution of all secondary minerals is virtually identical when only one or the other of the Ca-rich zeolite phases is considered. In addition, the two zeolite minerals exhibit virtually identical distribution patterns. For muscovite, the effect is to expand its occurrence in time and space, if stilbite is not present, although its absolute abundance is very low. In simulations where both are present, stilbite predominates over mesolite in abundance, the latter only occurring during the early period of the simulation.

is predominately affected by calcite and K-feldspar dissolution, and closely parallels those minerals in its overall distribution pattern. In the high temperature simulations, porosity change was on the order of $10 \%$ (relative) over the 100 year duration of the simulation. At lower flow velocities the changes are much lower (on the order of $1 \%$ relative).

\section{$\underline{\text { 2D Simulations }}$}

The principal changes that occur are dissolution of the initial phases (mainly calcite, but also feldspars and clay) and formation of zeolites and hydrated aluminous phases.

Fig. 8 shows the distribution of porosity, calcite, stilbite and mesolite after 5 years of GIMRT simulation, starting with thermal-hydrological conditions at 1,000 yrs. The location where condensate first interacts with rock is a region in which dissolution of calcite occurs and porosity increases. The region of dissolution tends to be relatively narrow vertically, but extends laterally throughout the region where significant condensate flux occurs because the solution is far from equilibrium with the minerals with which it is in contact, thus resulting in dissolution of the initial mineralogy. After a period of time, the length of which is determined by the dissolution kinetics of the initial mineral phases and the fluid flux, the solution tends to achieve concentration levels of dissolved species that are close to saturation values for secondary minerals to form and, hence, for calcite dissolution to diminish. Hence porosity will increase over distances of as many as several meters to tens of meters in the regions where condensate forms.

Zeolite formation consistently occurs in the lower condensate region 145-245 $\mathrm{m}$ above the water table (see Fig. 3). This phenomenon reflects the fact that saturation in the zeolite phases is only achieved after there has been sufficient contact time between the evolving condensate solution and 
the fracture mineralogy. The time needed to achieve this state is consistently satisfied within this zone where fracture fluxes drop to very low values and thus allow long contact times. Because the total mass flux through this region is small, the absolute abundance of secondary mineral phases formed in this region is also small. The conditions needed to result in saturation in a zeolite phase are also satisfied along some of the faster flow pathways, but the total quantity of material deposited is less.

Comparison of these results shows that the lower gas $\mathrm{CO}_{2}$ partial pressure represented by the atmospheric values, leads to subtle changes in the overall abundance of the primary and secondary minerals. In general, there is an absolute increase in the abundance of zeolites in the simulations using atmospheric $\mathrm{CO}_{2}$, but the differences are small. These differences reflect the fact that variation in $\mathrm{CO}_{2}$ partial pressure affects solution $\mathrm{pH}$ and carbonate-bicarbonate balance. Variations in these solution variables influence dissolution rates and metal speciation, both of which influence saturation conditions for the minerals considered here.

We also examined the impact of infiltration rate by running the same NUFT simulation with five times lower infiltration (results not shown). In general, lower flux values lead to smaller volumes of secondary minerals forming along the flow path. This reflects the fact that the extent of secondary mineral development is, in part, a function of the total mass flux. In addition, for lower flux values, the distribution of flux is more uniform in nonequilibrium thermal-hydrological models. Hence, the chemical alteration effects are, for a given volume of water, distributed through a larger volume of rock. 


\section{DISCUSSION}

\section{Pattern of Mineral and Porosity Evolution}

Mineral alteration is a clear function of the thermal hydrological environment, specifically with respect to the location of condensate formation regions. Fracture porosity is enhanced in those areas where condensate forms. Condensate zones are concentrated in two key areas (Fig. 1). One area is that above the reflux zone, approximately where the upper boiling-point isotherm will be. The other area is the lower condensate zone, just below the boiling isotherm.

The locations where mineral precipitation occurs and porosity decreases depend on the integrated residence time of the solution on the fracture surface. In general, low liquid-fluid fluxes are expected to occur in the region $\sim 150 \mathrm{~m}$ above the water table. Hence, it is expected that, within a few decades of the initiation of repository heating, secondary minerals, primarily zeolites, will form in that region, in those locations where fluid flow has been maintained. Secondary minerals are also expected to form, after several decades of fluid flow, within the pillars between emplacement drifts.

The predicted sequence of mineral changes is similar for all our simulations. The principal changes that occur are dissolution of the initial phases (mainly calcite, but also feldspars and clay) and formation of zeolites and hydrated aluminous phases. The lower the fluid velocity conditions at any particular location, the more concentrated the effects of reactions involving dissolution and precipitation. Major differences in mineral alteration occur over very short distances.

\section{Implications for water chemistry}

In all of the simulations, saturation in low solubility secondary minerals was achieved relatively quickly, due to the highly reactive nature of condensate. As a result, the solutions in equilibrium with the secondary phases remained dilute. This is consistent with the experimental work and other simulations reported on this rock material (Knauss and Peifer, 1986; Knauss et al., 1997; Johnson et al, 1998). Hence, it can be reasonably assumed that the waters that evolve within the regions around the potential repository will remain relatively dilute, provided the conditions are similar to those considered in this report. Exceptions to this case will be the region in the vicinity of the boiling front, where relatively high ionic strength solutions can form, and in those regions affected by materials used in construction of the repository, where much more complex and highly alkaline solutions may evolve due to the presence of cement.

\section{Implications for thermal-hydrological coupling}

The modifications in porosity noted in these simulations is relatively small. However, the impact of these changes on permeability remain unclear. If changes in porosity of more than $10 \%$ occur 
over a period of a few decades, permeability may sufficiently change and result in significant modification of flow characteristics, assuming that some form of a cubic law holds for typical coupling between porosity and permeability and neglecting thermomechanical effects. The impact of this effect on thermal budgets, flow fields, and mechanical stability remain to be evaluated. Conversely, small decreases in porosity are apparent in those regions where secondary minerals form. However, the results clearly show that the extent of porosity reduction is sensitive to the local flow conditions. In regions where flow is slow or stagnant, modification of the permeability structure will be most significant.

\section{Effect on Sorption}

Because redox reactions involving minerals that contain $\mathrm{Fe}$ or $\mathrm{Mg}$ were not considered in our modeling, the specific zeolite and clay mineral species predicted to precipitate (stilbite and mesolite, and kaolinite) may be partially or completely superseded by such species as clinoptilolite, heulandite, mordenite, or smectite clays. With respect to radionuclide transport, these differences in mineralogy may be significant.

Although secondary mineral development tends to be volumetrically minor in most of the considered region it is, nevertheless, almost ubiquitous. It must therefore be anticipated that most, if not all, fracture surfaces along a potential flow path will experience modification of the present day in situ mineralogy. In order to rigorously evaluate the retardation properties of the subrepository rock, it would therefore be necessary to conduct sorption experiments on materials that have been experimentally altered in a fashion similar to that anticipated along potential flow paths.

\section{$\underline{\text { Model Uncertainties and Limitations }}$}

An important issue that relates to this work is the accuracy of the thermodynamic data used in these calculations. Bruton (1995) has demonstrated, for example, that the thermodynamic properties of the silica polymorphs have an important influence on the results achieved in simulations such as those carried out here, which involve zeolites and other complex silicates. The implication of this point for the work presented here is that the exact geographical distribution, total abundance of a mineral phase, and the identity of a specific mineral phase is somewhat uncertain. Hence, whether stilbite per se forms in the distribution outlined is equivocal. However, we believe that the thermodynamic database is sufficiently robust to allow the conclusion to be reached that a zeolite (or zeolites) will form in approximately the distribution outlined here provided, of course, kinetic barriers do not interfere with nucleation and precipitation.

Recent work by Carroll et al. (1998) on amorphous silica $\left(\mathrm{SiO}_{2}\right)$ illustrates the difficulty of determining the precipitation rates of minerals in natural systems. This study was conducted to measure rates of precipitation in both field and laboratory experiments. The results of this study 
show that amorphous silica precipitation rates appeared to be controlled by distinct mechanisms in laboratory versus field studies. Rates from the Wairakei field study they conducted were 10-300 times higher than those predicted from laboratory experiments. Carroll et al. (1998) suggest that deviation in rates increased with increasing degree of supersaturation, and may have been influenced by the presence of dissolved solutes such as aluminum. They suggest that field rates may be accelerated by surface defect/surface nucleation effects associated with the incorporation of trace amounts of aluminum into the precipitate. These results indicate that laboratory measurements of precipitation rates may significantly underestimate the rates at which amorphous silica will form in the natural system when perturbed by repository heat. Our assumption that precipitation rates are equivalent in magnitude to, and opposite in sign from, dissolution rates provides a conservative overestimate of the rate of precipitate formation.

Also, boiling, which is not incorporated in our simulations, is expected to cause reduction of fracture porosity and permeability.

\section{$\underline{\text { Future Work }}$}

An important future direction for research is correlating predictive results such as those presented here with large scale field experiments, such as the thermal tests currently being conducted in the exploratory Studies Facility by the Yucca Mountain Project, and laboratory experiments. These studies could help to elucidate the sequence of mineral formation along identified flow paths along which temperature histories have been recorded.

Extension of these results to more complex chemical and mineralogical systems would also be of value. In particular, this would include consideration of redox effects, along with the addition of other potential secondary mineral phases, such as complex Fe-Mg - bearing clays and zeolites, and oxyhydroxide phases. Mineral precipitation/dissolution at the boiling front also needs to be considered.

In addition, more complex simulations, considering heterogeneous distributions of minerals along fracture surfaces, and the impact of solutions that interacted with materials used in the construction of repository drifts (e.g., cement), is needed.

We consider the results presented here to be an initial step in defining in detail those parameters that strongly influence mineral development. 


\section{CONCLUSIONS}

The purpose of this work was to examine the sensitivity of mineral change predicted by a reactive transport model to condensate properties, and specific flow and temperature scenarios. We have investigated the interaction of condensate water flowing through fractures within the potential repository at Yucca Mountain through a series of 1D and 2D reactive transport simulations. Our simulations show that the principal mineral changes that occur are dissolution of the initial phases (mainly calcite, but also feldspars and clay) and formation of zeolites and hydrated aluminous phases. Major differences in mineral alteration occur over very short distances.

Fracture mineral alteration is clearly coupled with the thermal hydrological environment. Fracture porosity is enhanced in those areas where condensate forms, an upper, lower temperature condensate zone and a lower, high temperature condensate zone. The locations where mineral precipitation occurs and porosity decreases depend on the integrated residence time of the solution on the fracture surface. Mineral precipitation is expected to occur in the region $\sim 150 \mathrm{~m}$ above the water table. Whether the changes in porosity are significant enough to modify thermohydrological behavior remains to be evaluated. In our simulations, water chemistry remained relatively dilute. This work is an initial step in predicting mineral alterations at Yucca Mountain. It is intended as a guide for developing simulation strategies for more refined, realistic representations of the physical system representative of the potential repository site. Future work needs to consider boiling, manmade materials (e.g., cement), redox reactions, the accuracy of the thermodynamic data and coupled thermomechanical behavior. Comparison of model results with field and laboratory work is also critical. 


\section{REFERENCES}

Bruton, C. J. (1995). "Testing EQ3/6 and GEMBOCHS Using Fluid-Mineral Equilibria in the Wairakei Geothermal System: Yucca Mountain Project Letter Report, Milestone MOL206," in Chemical and Mineralogical Properties of the Waste Package Environment: Natural System Simulations, WBS Element 1.2.3.12.1, August 28, 1995.

Buscheck, T.A., Gansemer, J., Delorenzo, T., Nitao, J.J., Shaffer, R.J., Cordery, M.J., Lee, K.H. (1997). Thermal-hydrological models of the distribution of temperature, relative humidity, and gas-phase air-mass fraction in repository drifts. Milestone SPLD1M4 and SPLD2M4, Yucca Mountain Project, Lawrence Livermore National Laboratory, Livermore, CA.

Carlos, B. (1994). Field guide to fracture-lining minerals, Yucca Mountain, Nevada. LA-12803MS. Los Alamos National Laboratory, Los Alamos, New Mexico. 12p.

Carroll, S., E. Mroczek, M. alai, and M. Ebert (1998). "Amorphous silica precipitation $\left(60^{\circ} \mathrm{C}\right.$ to $120^{\circ} \mathrm{C}$ ): Comparison of laboratory and field rates." Geochimica et Cosmochimica Acta (in press).

Civilian Radioactive Waste Management System Management \& Operating Contractor (CRWMS M\&O (1997). "Reference Design Description for a Geologic Repository", Rev. 1.

Delany, J.M. (1985). "Reaction of Topopah Spring Tuff with J-13 Water: A Geochemical Modeling Approach Using the EQ3/6 Reaction Path Modeling Code." (UCRL-53631). Livermore, CA: Lawrence Livermore National Laboratory. (48 pp.).

Glassley, W.E., and Laura DeLoach (1997). Second Quarter Results of Chemical Measurements in the Single Heater Test. Milestone SP9240M4, Yucca Mountain Project, Lawrence Livermore National Laboratory, Livermore, CA.

Glassley, W.E., and S. Boyd (1995). "Preliminary description of Small Block mineralogical features." Milestone report for the CRWMS Management and Operating Contractor, U.S. Department of Energy. (M0L062).

Hardin, E. L. et al. (1998). Near-Field/Altered-Zone Models Report, (UCRL-ID-129179 DRAFT). Livermore, CA: Lawrence Livermore National Laboratory.

Hardin, E.L., and D.A. Chesnut (1997). "Synthesis Report on Thermally Driven Coupled Processes." Milestone report for the CRWMS Management and Operating Contractor, U.S. Department of Energy. (SP3005MS). Livermore, CA: Lawrence Livermore National Laboratory. (Also UCRL-ID-128495, Lawrence Livermore National Laboratory, Livermore, CA).

Johnson, J.W., K.G. Knauss, W.E. Glassley, and L.D. DeLoach (in press). "Reactive transport modeling of plug-flow-reactor experiments: quartz and tuff dissolution at $240^{\circ} \mathrm{C}$." Journal of Hydrology.

Knauss, K.G., and D.W. Peifer (1986). "Reaction of Vitric Topopah Spring Tuff and J-13 Ground Water Under Hydrothermal Conditions, Using Dickson-Type, Bold-Bag Rocking Autoclaves." (UCRL-53795). Livermore, CA: Lawrence Livermore National Laboratory.

Knauss, K.G., W.J. Beiriger, and D.W. Peifer (1987). "Hydrothermal Interaction of Solid Wafers of Topopah Spring Tuff with J-13 Water and Distilled Water at 90 and $150^{\circ} \mathrm{C}$ Using Dickson-Type, Gold-Bag Rocking Autoclaves: Long-Term Experiments." (UCRL53722). Livermore, CA: Lawrence Livermore National Laboratory. 
Lichtner, P.C. (1992). "Time-space continuum description of fluid/rock interaction in permeable media." Water Resour. Res. 28:3134-3155.

Nitao, J.J. (1995). Reference manual for the NUFT flow and transport code, Version 1.0. Livermore, CA: Lawrence Livermore National Laboratory. (UCRL-IC-113520).

Paces, J.B. et al. (1997). Progress Report on Unsaturated Zone Stable and Radiogenic Isotope Studies, USGS Level 4 Mileston SPC23FM4.

Steefel, C.I. (1993). “IDREACT: One-dimensional reaction-transport model: User manual and programmer's guide." unpublished manuscript. Richland, WA: Pacific Northwest Laboratory, Battelle Memorial Institute. (42 pp.).

Steefel, C.I. and Yabusaki, S.B. (1995). OS3D/GIMRT: Software for modeling multicomponentmultidimensional reactive transport. Pacific Northwest Laboratory, Richland, Washington.

Steefel, C.I., and A.C. Lasaga (1994). "A coupled model for transport of multiple chemical species and kinetic precipitation/dissolution reactions with application to reactive flow in single-phase hydrothermal systems.” Amer. J. Sci. 294:529-592.

Vaniman, D.T., D.L. Bish, S.J. Chipera, B.A. Carlos, and S.G. Jr. (1997). "Summary and synthesis report on mineralogy and petrology studies for the Yucca Mountain Site Characterization Project." Milestone report for the CRWMS Management and Operating Contractor, U.S. Department of Energy. (3665). Los Alamos, NM: Los Alamos National Laboratory.

Wolery, T.J. (1992a). EQ3/6, A Software Package for Geochemical Modeling of Aqueous Systems: Package Overview and Installation Guide. Lawrence Livermore National Laboratory, Livermore, CA UCRL-MA-110662 PT. I

Wolery, T.J. (1992b). EQ3NR, A Geochemical Program For Aqueous Speciation-Solubility Calculations: Theoretical Manual, User's Guide, and Related Documentation. Lawrence Livermore National Laboratory, Livermore, CA UCRL-MA-110662 PT. III

Wolery, T.J., and S. A. Daveler (1992). EQ6, A Computer Program for Reaction Path Modeling of Aqueous Geochemical Systems: Theoretical Manual, User's Guide, and Related Documentation (Version 7.0). Lawrence Livermore National Laboratory, Livermore, CA UCRL-MA-110662 PT. IV

Yang, I.C., A.K. Turner, T.M. Sayre, and P. Montazar (1988). "Triaxial-Compression Extraction of Pore Water from Unsaturated Tuff, Yucca Mountain, Nevada." Water Resources Investigations Report. (88-4189). U.S. Geological Survey. 
Table 1. Model Mineral Phases and Distribution

\begin{tabular}{|c|c|c|}
\hline Minerals & $\begin{array}{c}1 D \\
\text { (in volume fraction) }\end{array}$ & $\begin{array}{c}2 D \\
\text { (in volume fraction) }\end{array}$ \\
\hline Albite & .001 & .000005 \\
\hline K-Feldspar & .001 & .00001 \\
\hline Quartz & .05 & .0001 \\
\hline $\mathrm{SiO} 2$ (amorphous) & .05 & ----- \\
\hline Kaolinite & .001 & .00001 \\
\hline Calcite & .7 & .0095 \\
\hline Cristobalite (alpha) & 0 & .0001 \\
\hline Chalcedony & 0 & ----- \\
\hline Diaspore & 0 & 0 \\
\hline Muscovite & 0 & ----- \\
\hline Paragonite & 0 & ----- \\
\hline Pyrophyllite & 0 & ----- \\
\hline Mesolite & ---- & 0 \\
\hline Stilbite & 0 & 0 \\
\hline Porosity & .17 & .990275 \\
\hline
\end{tabular}


Table 2. Model Fluid Composition

\begin{tabular}{l|ll}
\hline Species & elevated $\mathrm{CO}_{2}$ simulations & atm $\mathrm{CO}_{2}$ simulations \\
\hline & $\mathrm{pH}=5.15$ & $\mathrm{pH}=5.7$ \\
$\mathrm{H}^{+}$ & $<10^{-8} \mathrm{M}$ & $<10^{-8} \mathrm{M}$ \\
$\mathrm{Al}^{+++}$ & $<10^{-8} \mathrm{M}$ & $<10^{-8} \mathrm{M}$ \\
$\mathrm{SiO}_{2}(\mathrm{aq})$ & $<10^{-8} \mathrm{M}$ & $<10^{-8} \mathrm{M}$ \\
$\mathrm{Na}^{+}$ & $<10^{-8} \mathrm{M}$ & $<10^{-8} \mathrm{M}$ \\
$\mathrm{K}^{+}$ & $<10^{-8} \mathrm{M}$ & $<10^{-8} \mathrm{M}$ \\
$\mathrm{Ca}^{++}$ & $7.11 \mathrm{e}-6 \mathrm{M}$ & $2.1 \mathrm{e}-6 \mathrm{M}$ \\
$\mathrm{HCO}_{3}^{-}$ & \\
\hline
\end{tabular}


Table 3. Model Thermodynamic Data

\begin{tabular}{|c|c|c|c|c|}
\hline Minerals & $\begin{array}{c}\text { Rate } \\
\text { Constant } \\
\text { moles } / m^{2} \\
\text {-sec, } 25^{\circ} \mathrm{C}\end{array}$ & $\begin{array}{c}\text { Activation } \\
\text { Energy } \\
\text { kcal/mole }\end{array}$ & $\begin{array}{c}\text { Surface Area } \\
\mathrm{m}^{2} / \mathrm{m}^{3} \text { of rock } \\
1 D\end{array}$ & $\begin{array}{c}\text { Surface Area } \\
\mathrm{m}^{2} / \mathrm{m}^{3} \text { of rock } \\
2 D\end{array}$ \\
\hline Albite & $1 \mathrm{e}-12$ & 16.2 & $4 \mathrm{e} 4$ & 100 \\
\hline K-Feldspar & $1 \mathrm{e}-12$ & 13.8 & $7.858 \mathrm{e} 4$ & 100 \\
\hline Quartz & $1.259 \mathrm{e}-14$ & 20.9 & $2.67 \mathrm{e} 4$ & 10 \\
\hline $\mathrm{SiO} 2$ (amorphous) & $8 e-12$ & 15 & 10 & --- \\
\hline Kaolinite & $1 \mathrm{e}-13 *$ & $15 *$ & 10 & 100 \\
\hline Calcite & $1 e-11$ & 10 & 100 & 1000 \\
\hline Cristobalite (alpha) & $3.467 \mathrm{e}-13$ & 16.47 & $1.103 \mathrm{e} 5$ & 100 \\
\hline Chalcedony & $6 e-13$ & 15 & 10 & --- \\
\hline Diaspore & $3 e-13 *$ & $15 *$ & 10 & 100 \\
\hline Muscovite & $1 \mathrm{e}-14 *$ & 15 & 10 & -- \\
\hline Paragonite & $1 \mathrm{e}-14 *$ & 15 & 10 & -- \\
\hline Pyrophyllite & $1 \mathrm{e}-13 *$ & $15 *$ & 10 & -- \\
\hline Mesolite & $3 e-13$ & 15 & --- & 100 \\
\hline Stilbite & $3 e-13$ & 15 & 10 & 100 \\
\hline
\end{tabular}

*Data are taken from Johnson et al. (1998) where noted. Other data represent our best judgement based on the Johnson et al. (1998) values. See text for additional details. 


\section{Figure Captions}

Fig. 1. Geochemical Regimes at Potential Repository.

Four distinct geochemical regions can be identified given the predicted thermal-hydrological behavior at Yucca Mountain: (1) the lower, high temperature condensate zone, (2) the pillar region, (3), the reflux zone, and (4) the upper, low temperature condensate zone. This figure shows a generalized view of these regions which are expected to vary in space and time. At early times under some repository designs, the reflux zone may extend into the area above the pillar region.

Fig. 2. 1D Model Domain, Temperature and Flow Fields.

The 1D simulations were performed on a 20 cell nonuniform mesh representing a column $33 \mathrm{~m}$ high, as shown. Two temperature fields were considered. The high temperature field reflects conditions in the lower, high temperature condensate zone (Fig. 1). The top $5 \mathrm{~m}$ of the high temperature field are representative of conditions in the reflux zone as well. The low temperature field reflects conditions in the upper, low temperature condensate zone (Fig. 1). The flow field was uniform and constant. We considered velocities ranging from $0.1-1,000 \mathrm{~m}^{3} \mathrm{~m}^{-2} \mathrm{yr}^{-1}$.

Fig. 3. 2D Model Domain, Temperature and Flow Fields.

The 2D simulations were performed on a 1334 cell uniform mesh representing a vertical crosssection $14.5 \mathrm{~m}$ wide and $736 \mathrm{~m}$ high. The emplacement drift center is approximately half-way along the left hand side. The temperature and flow field (fracture continuum flow multiplied by saturation) were taken from drift-scale thermohydrologic simulations for a reference case repository design using a coupled thermal hydrological computer code (NUFT) (Nitao, 1995; Hardin et al., 1998). No reactive transport was allowed to occur in the shaded areas. See text for details.

Fig. 4. 1D Simulation Results for Low Temperature Field and Flux of $100 \mathrm{~m}^{3} \mathrm{~m}^{-2} \mathrm{yr}^{-1}$.

Calcite, K-feldspar, stilbite (volume percent) and porosity are shown as functions distance travelled along the fracture (increasing from top to bottom) and simulation time.

Fig. 5. 1D Simulation Results for High Temperature Field and Flux of $100 \mathrm{~m}^{3} \mathrm{~m}^{-2} \mathrm{yr}^{-1}$.

Calcite, K-feldspar, stilbite (volume percent) and porosity are shown as functions distance travelled along the fracture (increasing from top to bottom) and simulation time.

Fig. 6. 1D Simulation Results for Low Temperature Field and Flux of $1000 \mathrm{~m}^{3} \mathrm{~m}^{-2} \mathrm{yr}^{-1}$.

Calcite, K-feldspar, stilbite (volume percent) and porosity are shown as functions distance travelled along the fracture (increasing from top to bottom) and simulation time. 
Fig. 7. 1D Simulation Results for High Temperature Field and Flux of $1000 \mathrm{~m}^{3} \mathrm{~m}^{-2} \mathrm{yr}^{-1}$.

Calcite, K-feldspar, stilbite (volume percent) and porosity are shown as functions distance travelled along the fracture (increasing from top to bottom) and simulation time.

Fig. 8. 2D Model Results for Elevated $\mathrm{CO}_{2}$ Simulation

$\mathrm{CO}_{2}$ partial pressures is 0.1 bar, about 3 times atmospheric. Calcite, stilbite, mesolite (volume percent) and porosity fields are shown. Refer to Fig. 3 for description of model domain.

Fig. 9. 2D Model Results for Atmospheric $\mathrm{CO}_{2}$ Simulation.

Calcite, stilbite, mesolite (volume percent) and porosity fields are shown. Refer to Fig. 3 for description of model domain. 
ground surface

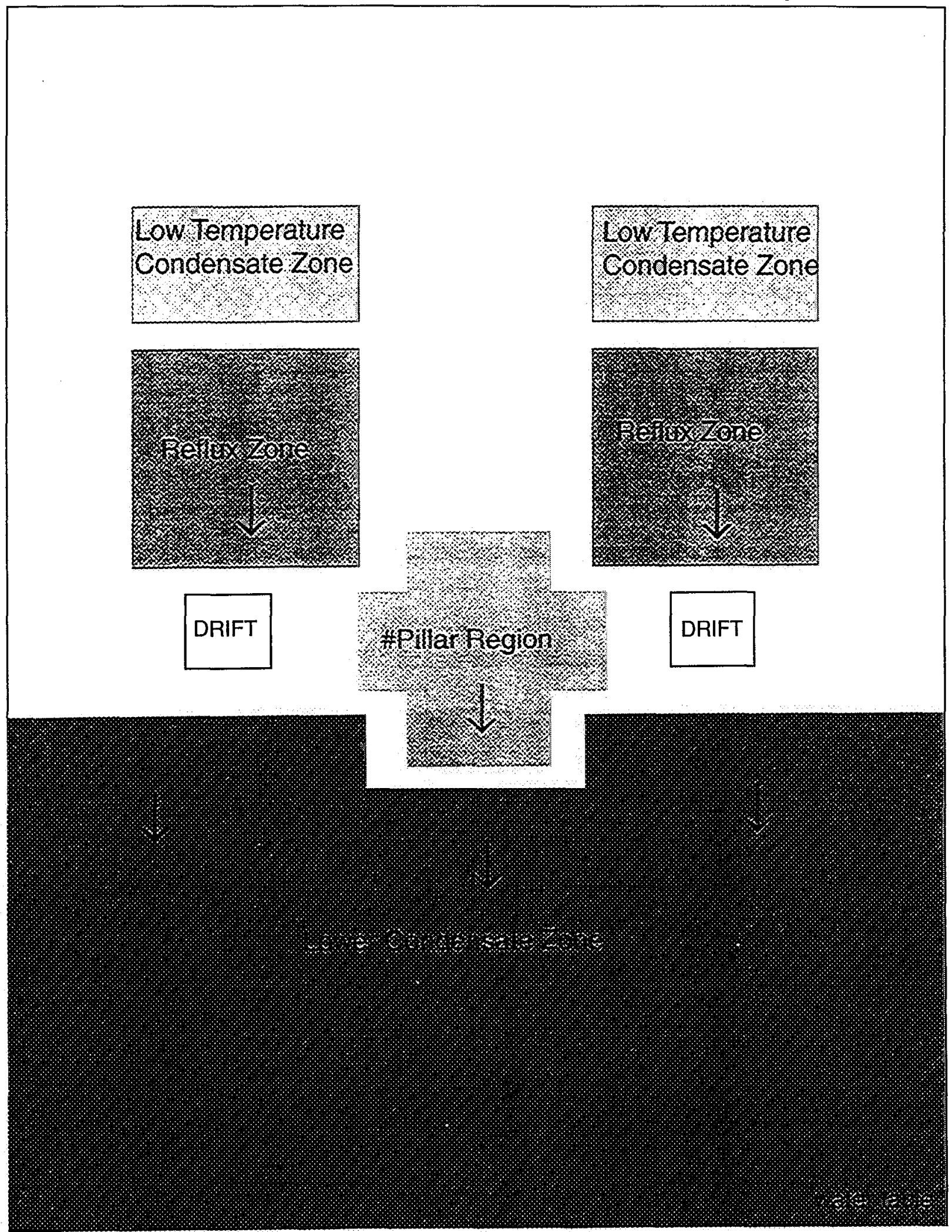




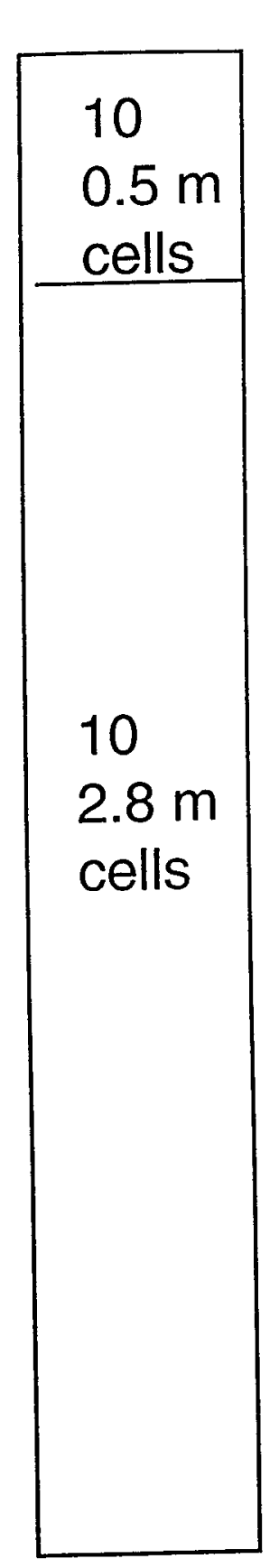

Mesh

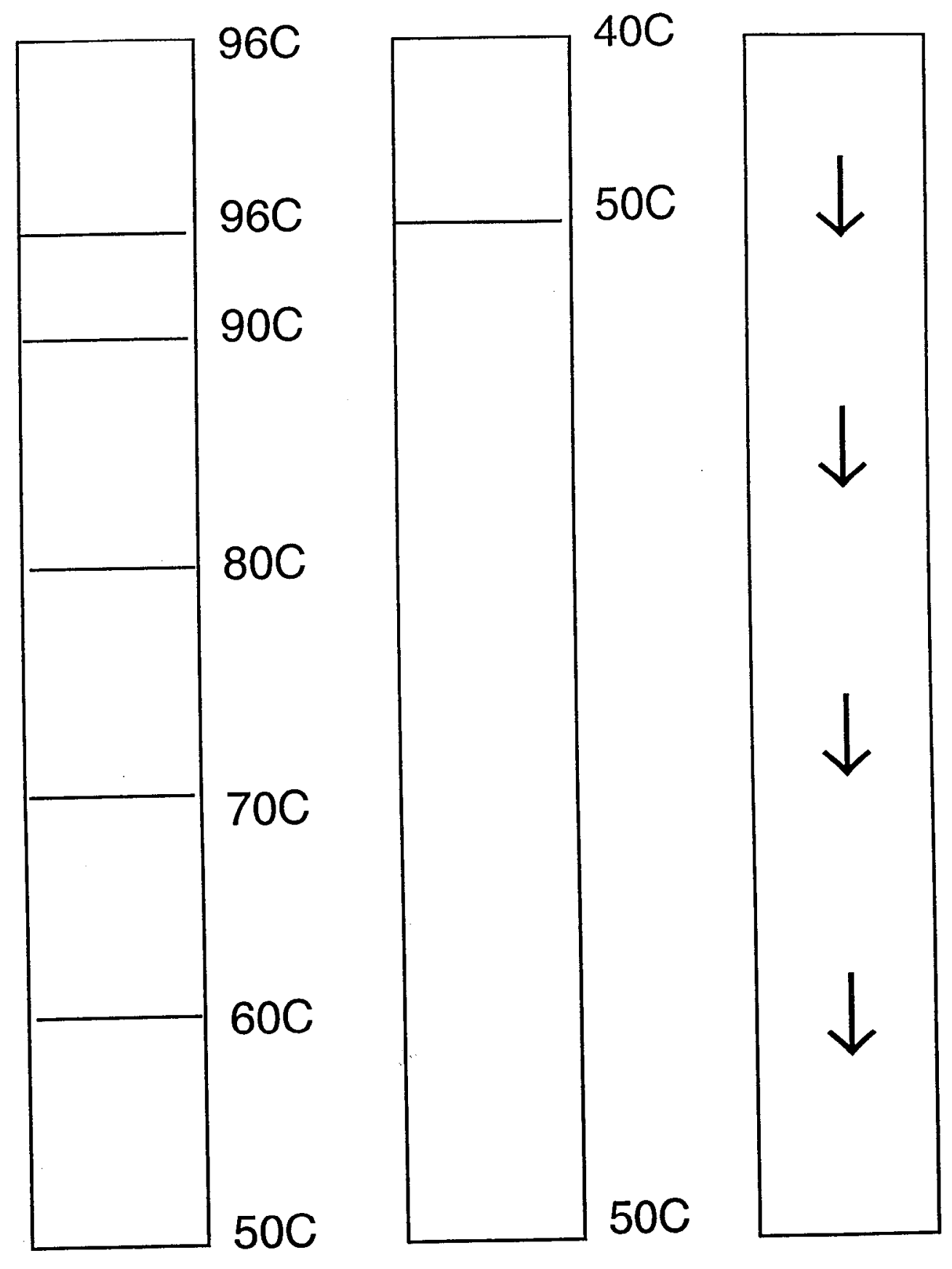

Temperature Temperature Uniform, Constant Field-High Field-Low Flow Field $\left(0.1-1000 \mathrm{~m}^{3} / \mathrm{m}^{2} / \mathrm{yr}\right)$ 
Temperature Field

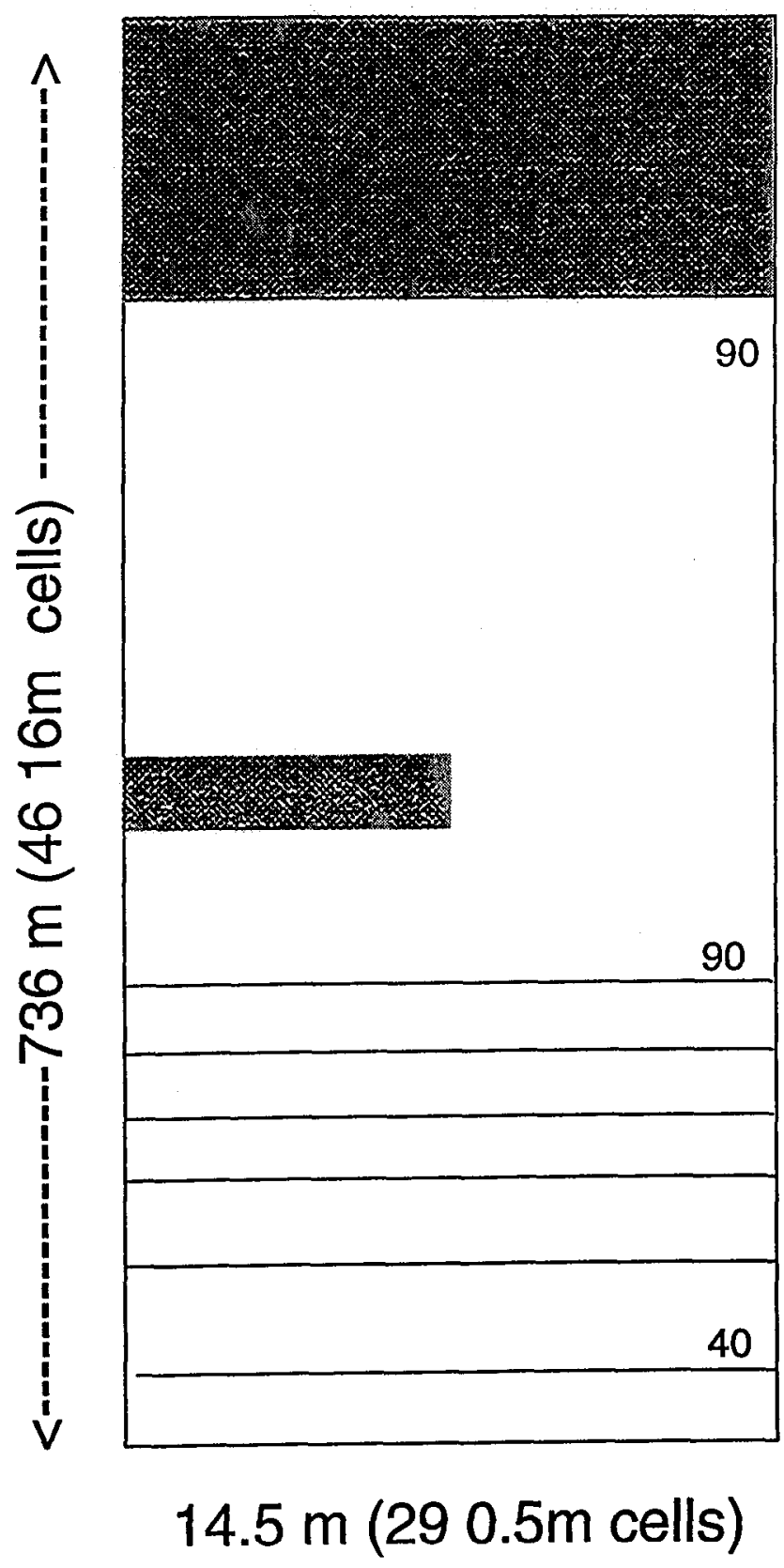

Flow Field

\begin{tabular}{|c|c|c|c|c|c|c|c|c|c|}
\hline & . & . & . & . & . & & . & . & \\
\hline 1 & 1 & 1 & 1 & 1 & 1 & 1 & 1 & 1 & 1 \\
\hline$\downarrow$ & 1 & 1 & $t$ & $t$ & 1 & $t$ & $t$ & 1 & 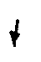 \\
\hline 1 & 1 & 1 & 1 & 1 & 1 & 1 & 1 & 1 & 1 \\
\hline 1 & $\downarrow$ & $t$ & $t$ & $\downarrow$ & $\downarrow$ & $t$ & $t$ & $t$ & $t$ \\
\hline$\downarrow$ & $\downarrow$ & $t$ & $t$ & $\downarrow$ & $\downarrow$ & $t$ & $t$ & $t$ & t \\
\hline 1 & $\downarrow$ & t & t & $t$ & $\downarrow$ & 1 & $t$ & $\downarrow$ & $\downarrow$ \\
\hline$t$ & $\downarrow$ & $\downarrow$ & $\downarrow$ & $\downarrow$ & $\downarrow$ & $\downarrow$ & $\downarrow$ & $t$ & $\downarrow$ \\
\hline$\downarrow$ & $t$ & 1 & 1 & 1 & 1 & 1 & $\downarrow$ & 1 & $\downarrow$ \\
\hline$t$ & $\downarrow$ & 1 & 1 & 1 & 1 & 1 & 7 & 1 & $\downarrow$ \\
\hline 1 & 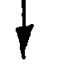 & 1 & 1 & 1 & $\downarrow$ & 1 & 7 & $\gamma$ & 1 \\
\hline · & ' & $r$ & 1 & $\downarrow$ & $t$ & $\downarrow$ & $\downarrow$ & $\downarrow$ & $\downarrow$ \\
\hline ' & , & 1 & 1 & ' & 1 & $t$ & $t$ & 1 & 1 \\
\hline 1 & 1 & 1 & 1 & 1 & 1 & 1 & 1 & 1 & 1 \\
\hline$d$ & 1 & 1 & 1 & 1 & 1 & 1 & $t$ & $t$ & $t$ \\
\hline - & . & . & . & ${ }^{\circ}$ & " & . & - & . & - \\
\hline & $\downarrow$ & $\downarrow$ & $\downarrow$ & $\downarrow$ & $\downarrow$ & $\downarrow$ & $\downarrow$ & $\downarrow$ & 7 \\
\hline 1 & 1 & $t$ & $t$ & $t$ & 1 & 1 & 1 & $t$ & 1 \\
\hline$\checkmark$ & $\downarrow$ & $\downarrow$ & $\downarrow$ & $\downarrow$ & $\downarrow$ & $\downarrow$ & $\downarrow$ & $\downarrow$ & $t$ \\
\hline$\downarrow$ & $\downarrow$ & $\downarrow$ & $\downarrow$ & $t$ & $t$ & $\downarrow$ & & & $\downarrow$ \\
\hline 1 & 1 & 1 & 1 & 1 & 1 & 1 & 1 & $t$ & \\
\hline
\end{tabular}

\section{BASED ON THERMAL HYDROLOGICAL MODEL (NUFT) OUTPUT AT 1000 YEARS}


Figure 4

Calcite (Volume \%)
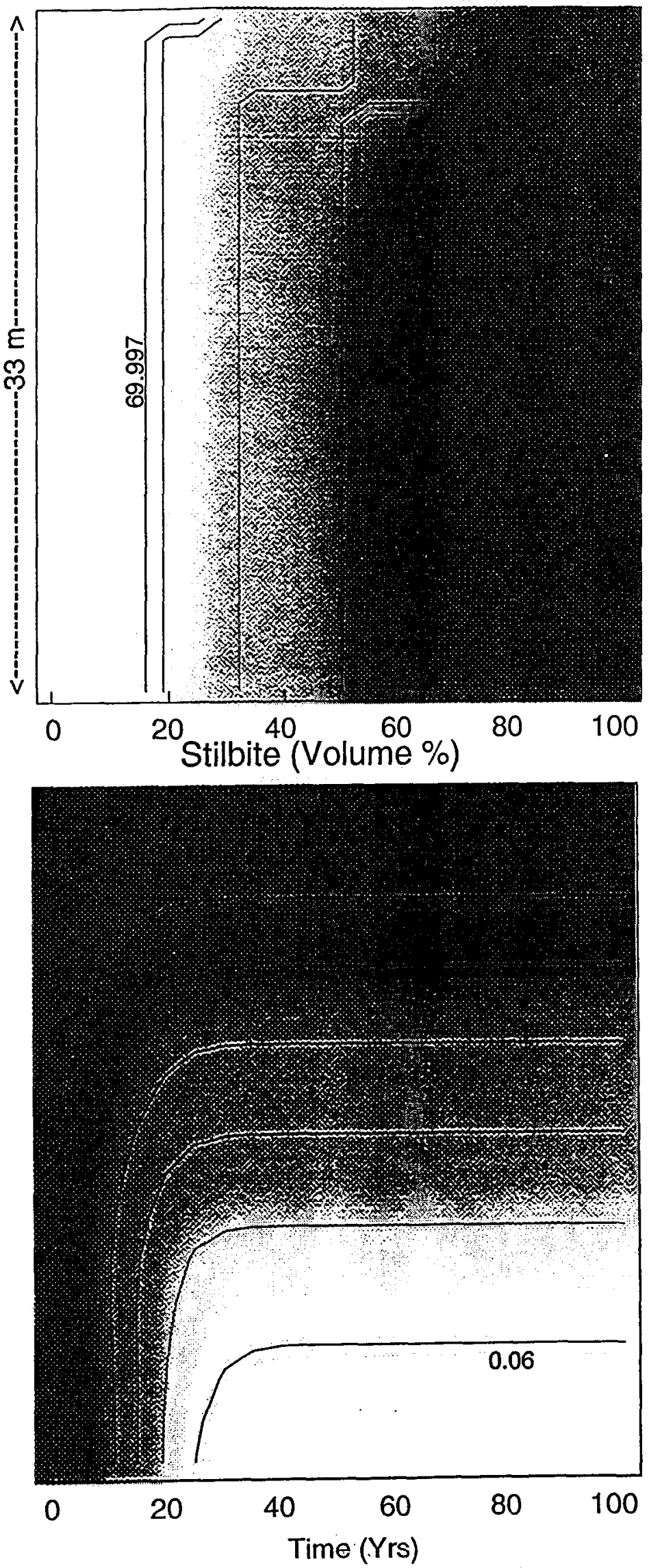

K-Feldspar (Volume \%)
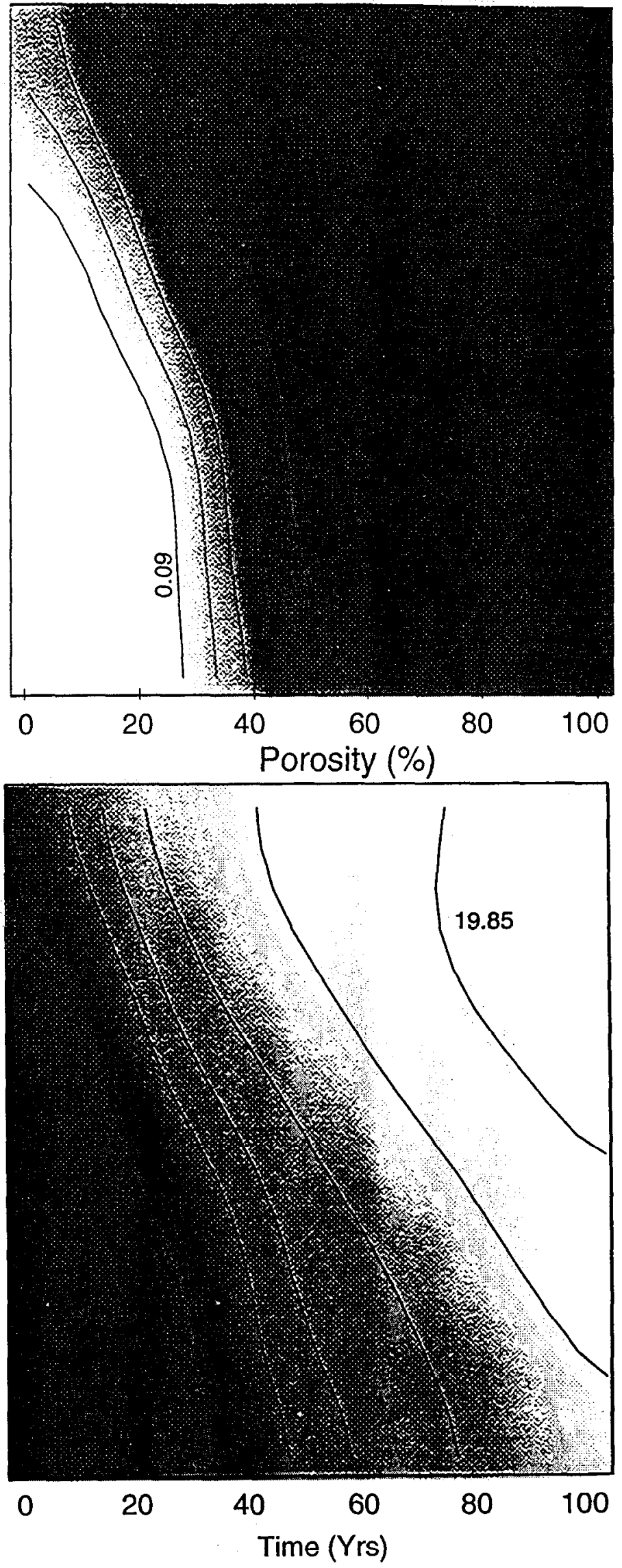

1D Low Temperature Simulation Results $F / u x=100 \mathrm{~m} 3 / \mathrm{m} 2 / \mathrm{yr}$ 


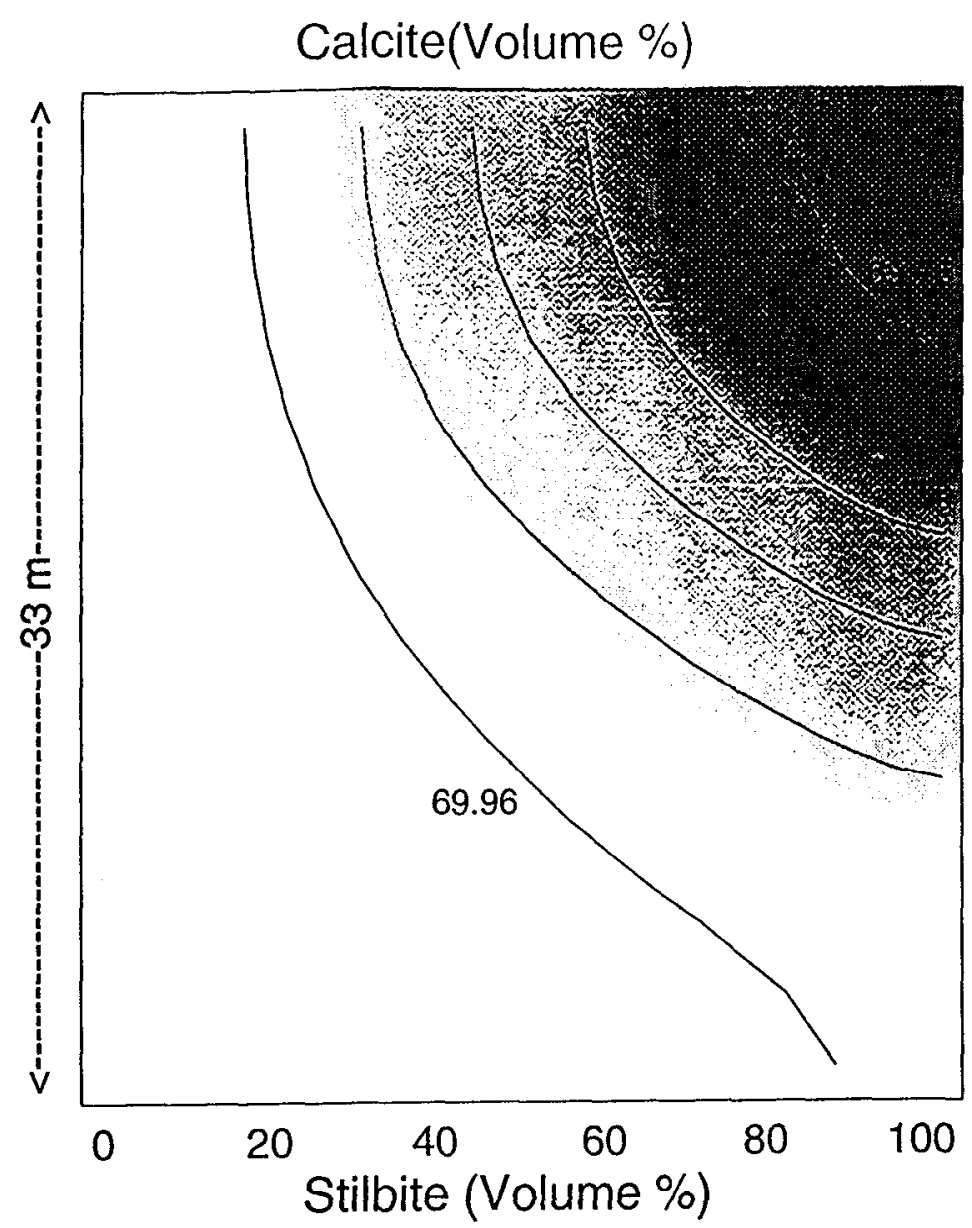

K-Feldspar (Volume \%)

Figure 5
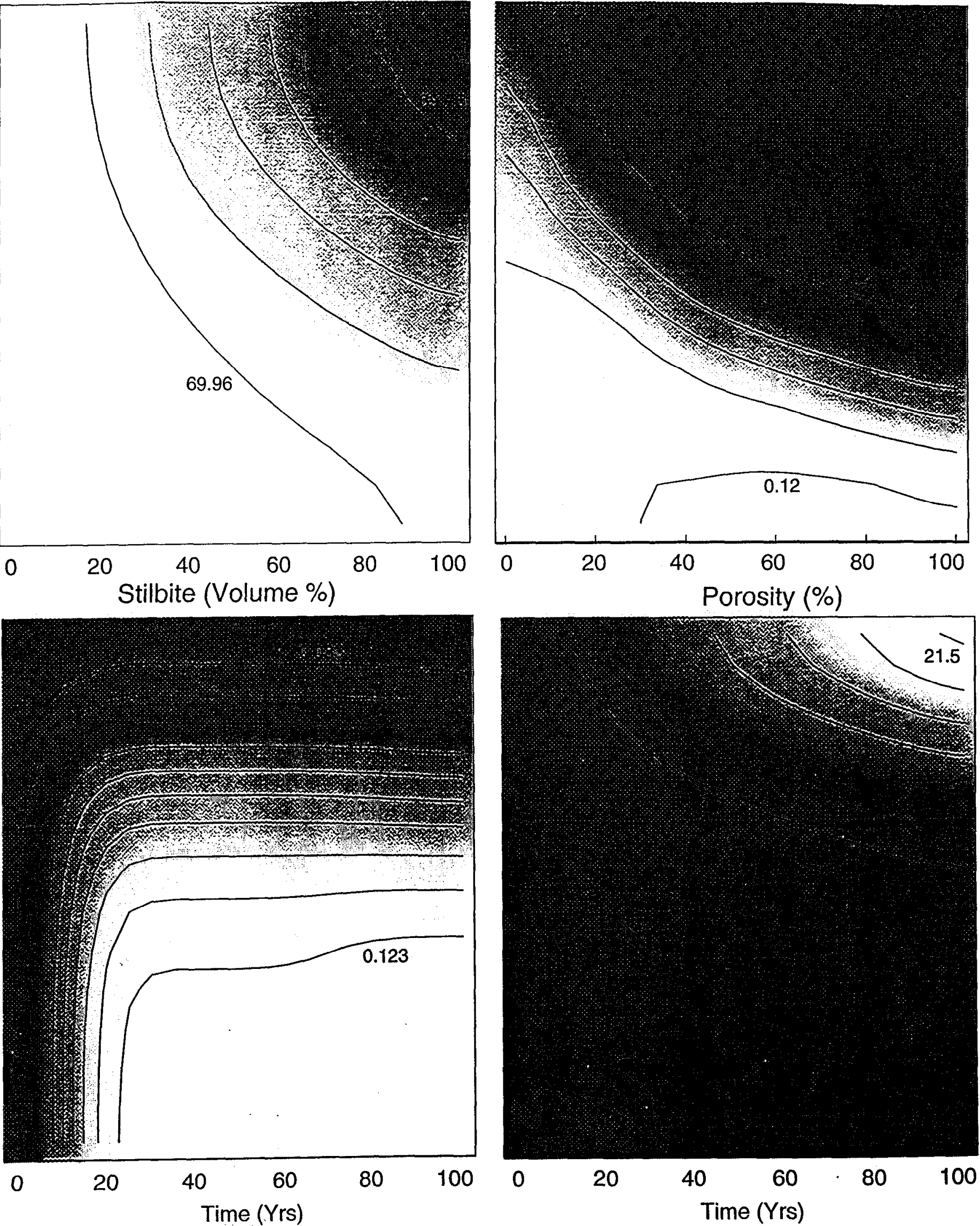

1D High Temperature Simulation Results Flux $=100 \mathrm{~m} 3 / \mathrm{m} 2 / \mathrm{yr}$ 

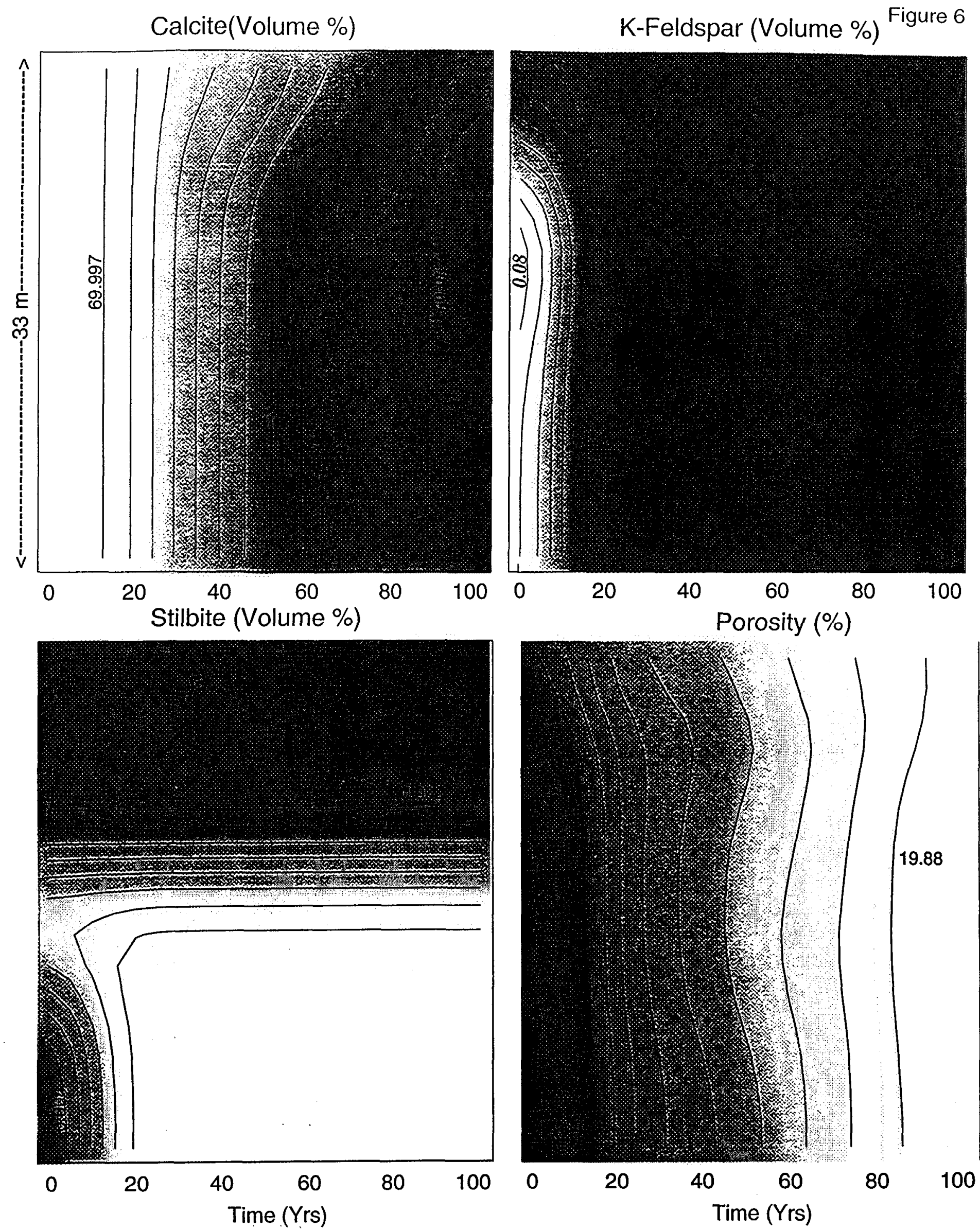

1D Low Temperature Simulation Results Flux $=1000 \mathrm{~m} 3 / \mathrm{m} 2 / \mathrm{yr}$ 

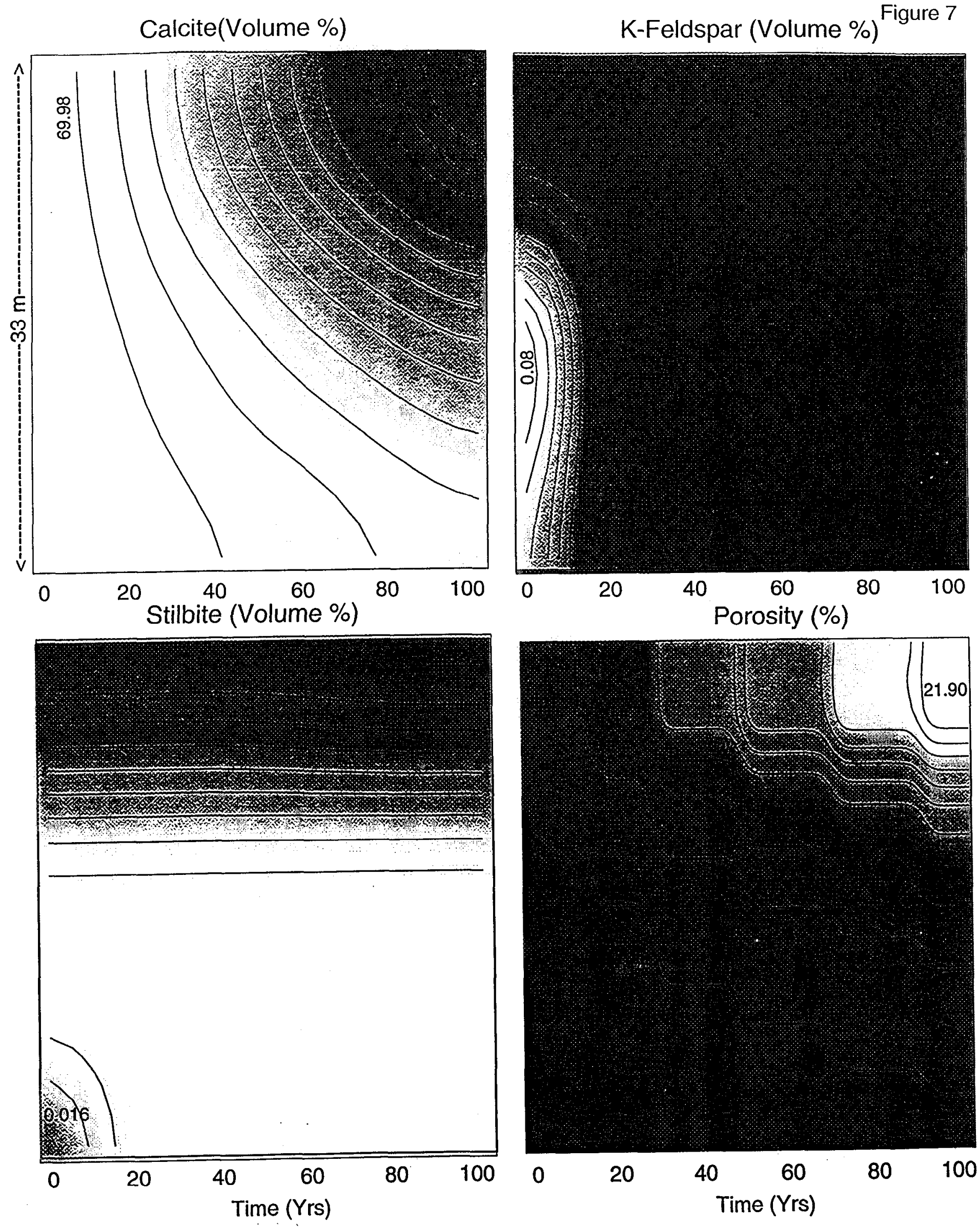

10 High Temperature Simulation Results Flux $=1000 \mathrm{m3} / \mathrm{m} 2 / \mathrm{yr}$ 

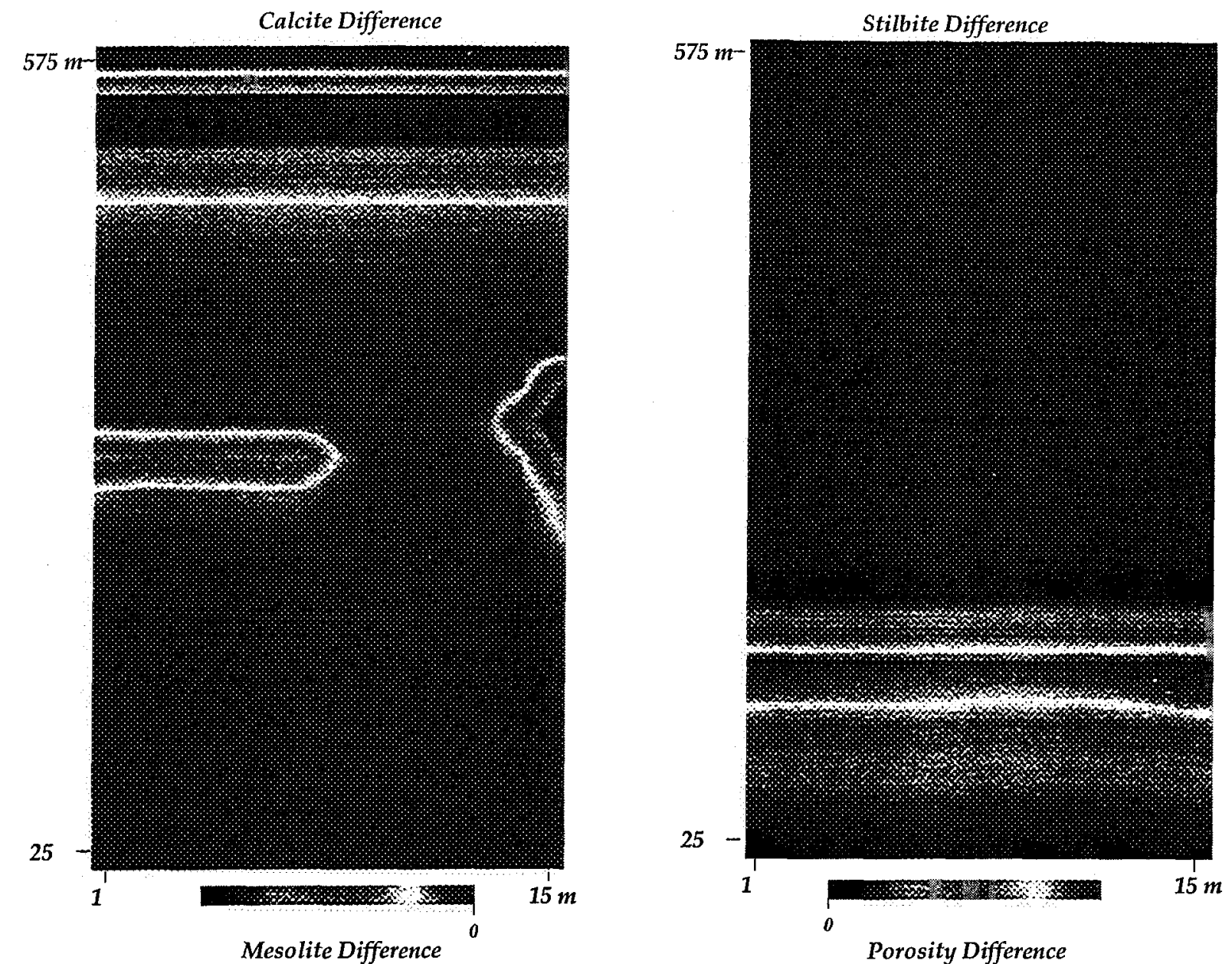

Figure 8
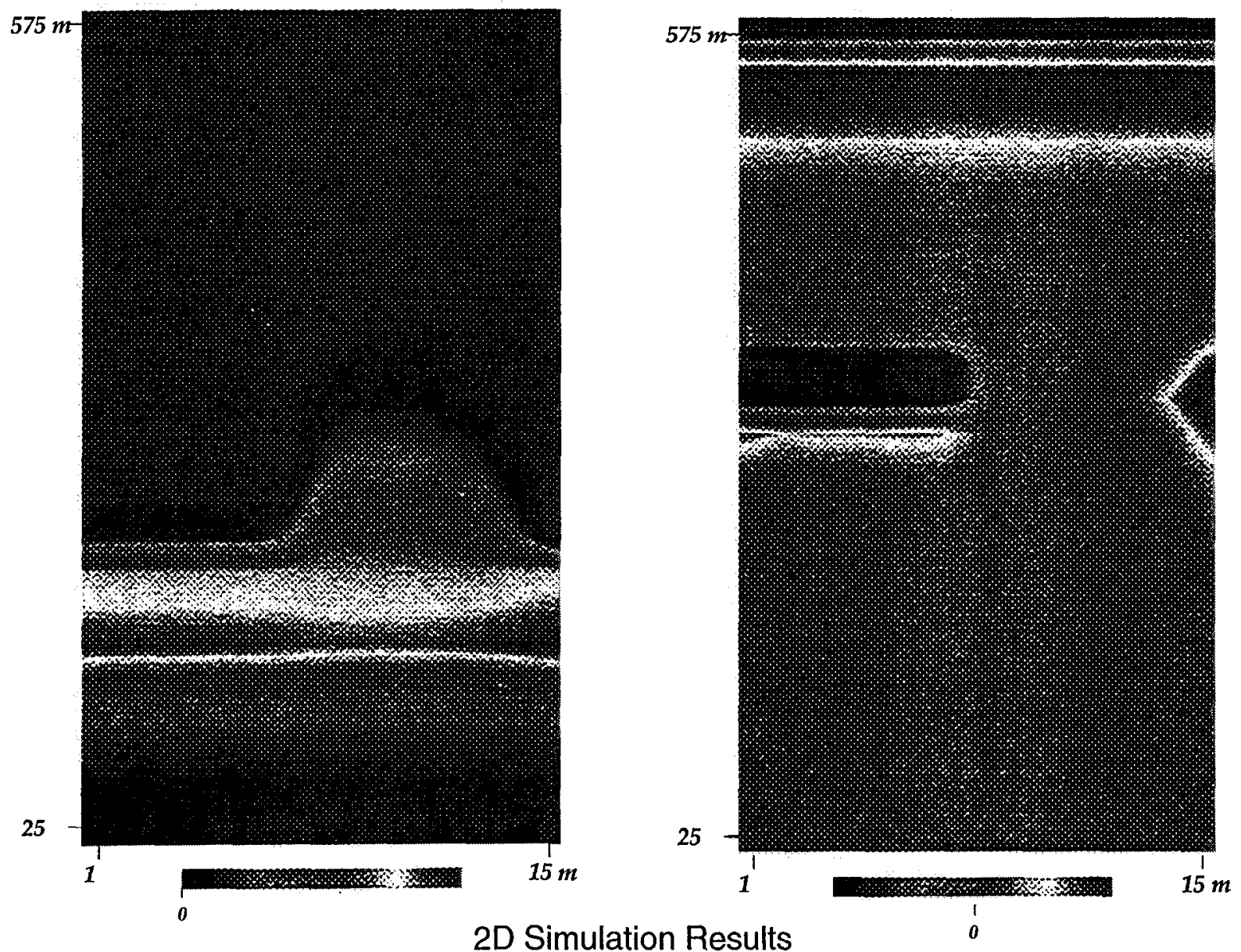

2D Simulation Results Elevated $\mathrm{CO} 2$ 
Calcite Difference

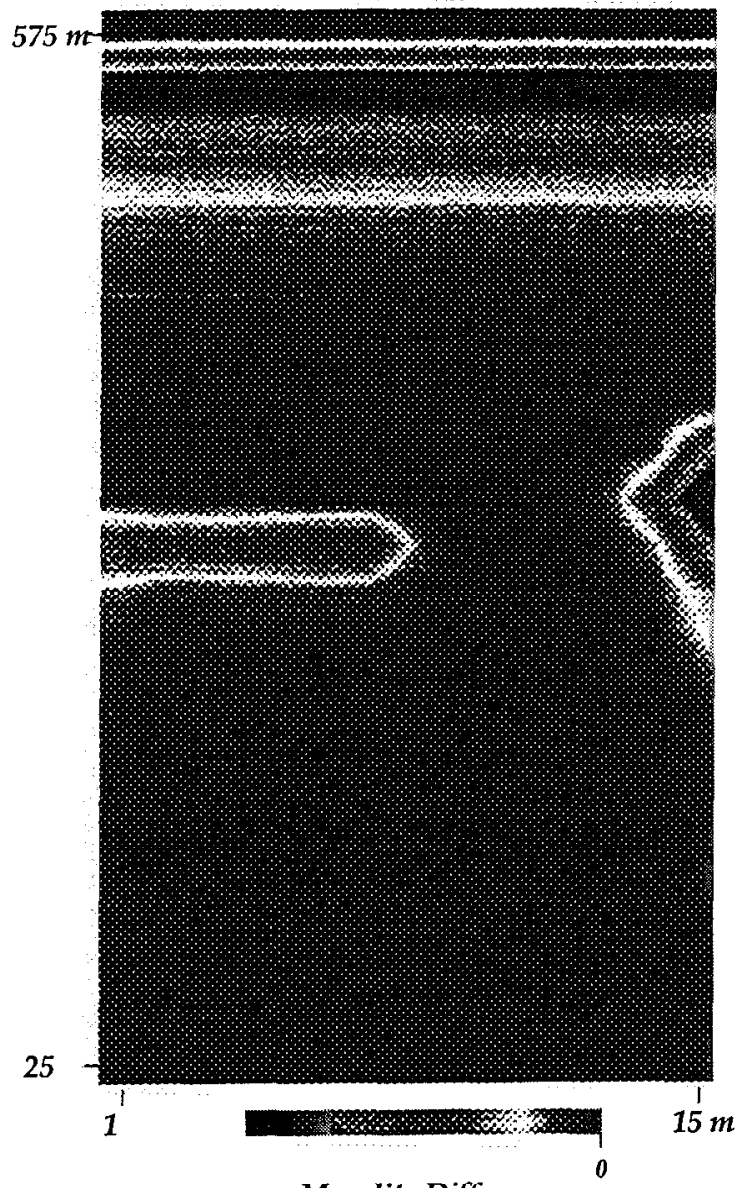

Mesolite Difference

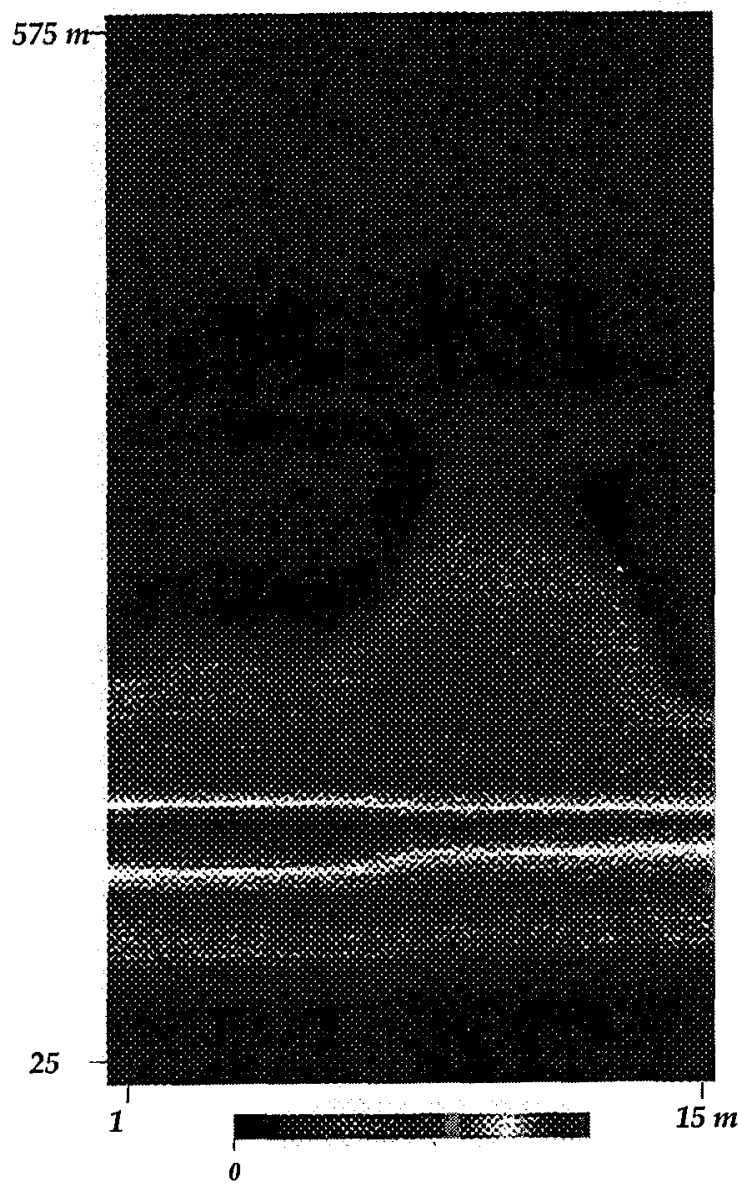

2D Simulation Results

Atmospheric $\mathrm{CO} 2$
Figure 9

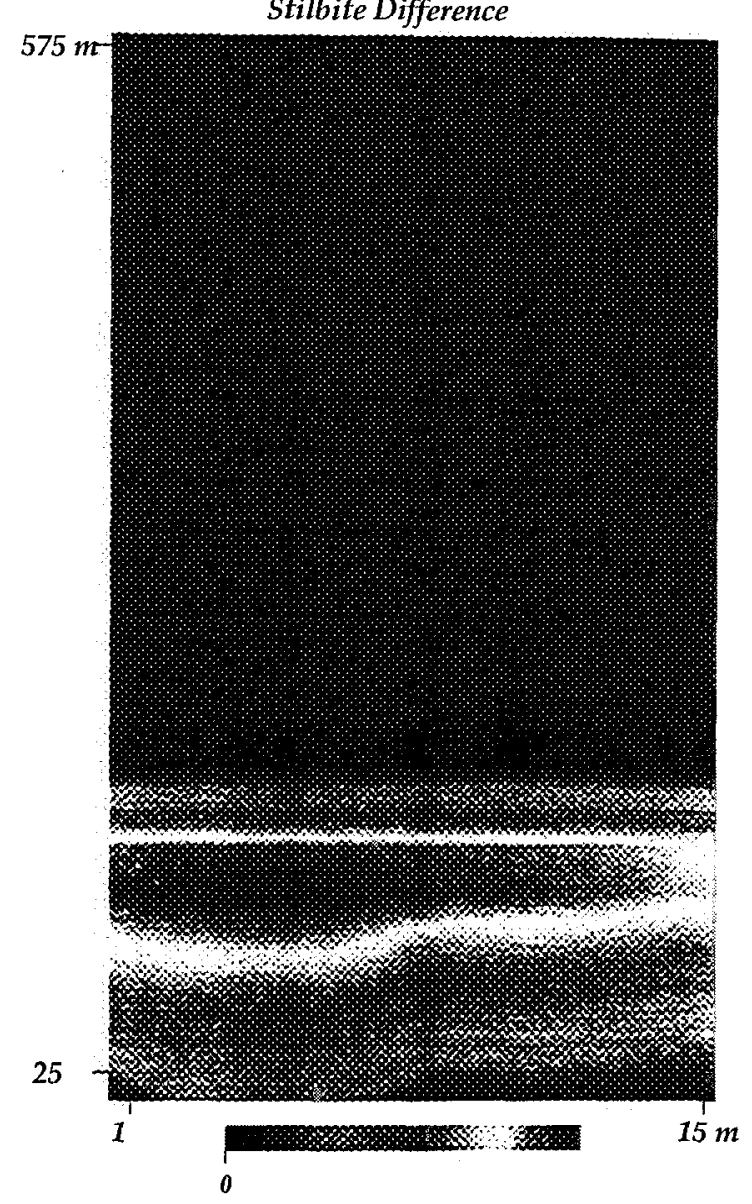

Porosity Difference

$575 m$
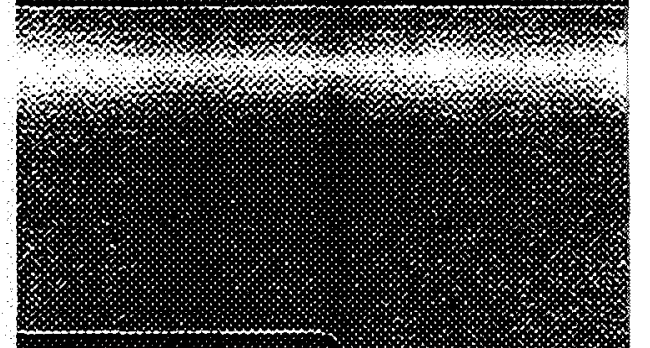

25

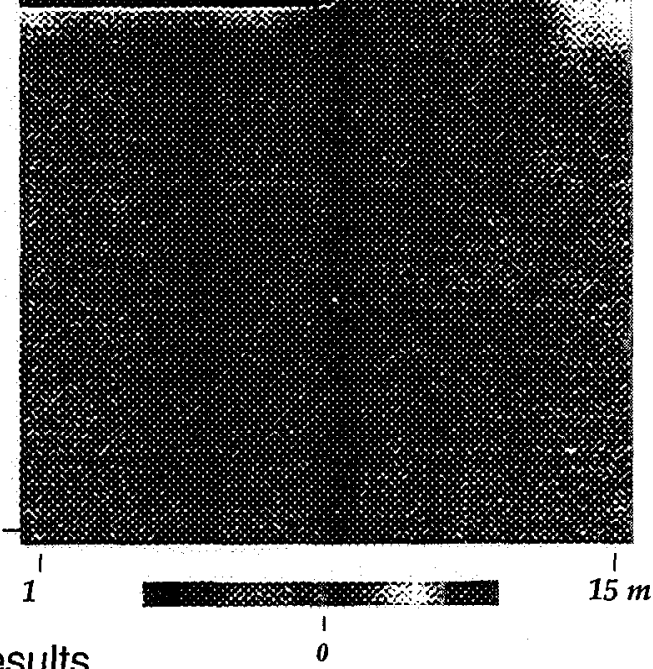




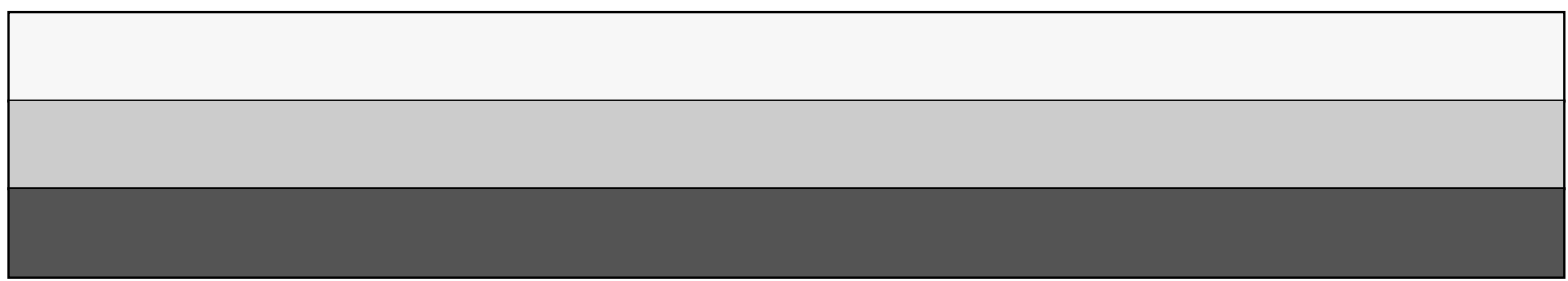

